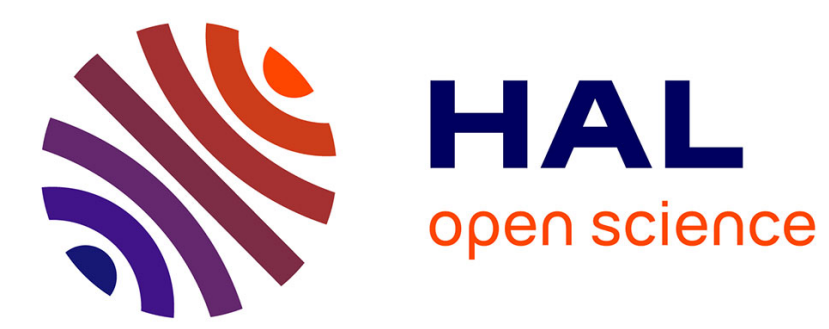

\title{
The Virtuous Cycle of Agreement
}

Philippos Louis, Matias Nunez, Dimitrios Xefteris

\section{To cite this version:}

Philippos Louis, Matias Nunez, Dimitrios Xefteris. The Virtuous Cycle of Agreement. The Economic Journal, 2021, 132 (641), pp.326-360. 10.1093/ej/ueab057 . halshs-03324190

\section{HAL Id: halshs-03324190 \\ https://shs.hal.science/halshs-03324190}

Submitted on 21 Dec 2021

HAL is a multi-disciplinary open access archive for the deposit and dissemination of scientific research documents, whether they are published or not. The documents may come from teaching and research institutions in France or abroad, or from public or private research centers.
L'archive ouverte pluridisciplinaire HAL, est destinée au dépôt et à la diffusion de documents scientifiques de niveau recherche, publiés ou non, émanant des établissements d'enseignement et de recherche français ou étrangers, des laboratoires publics ou privés. 


\title{
The Virtuous Cycle of Agreement*
}

\section{Philippos Louis ${ }^{\dagger}$}

University of Cyprus
Matías Núñez

CREST \& Ecole Polytechnique
Dimitrios Xefteris ${ }^{\S}$

University of Cyprus

March 2021

\begin{abstract}
Collective choice mechanisms are used by groups to reach decisions in the presence of diverging preferences. But can the employed mechanism affect the degree of post-decision actual agreement (i.e. preference homogeneity) within a group? And if so, which are the features of the choice mechanisms that matter? Since it is difficult to address these questions in natural settings, we employ a theory-driven experiment where, after the group collectively decides on an issue, individual preferences can be properly elicited. We find that decision mechanisms that promote consensual behavior generate substantially higher levels of post-decision actual agreement compared to outcome-wise identical procedures that incentivize subjects to exaggerate their differences.
\end{abstract}

JEL classification codes: D71, D72, D91.

Keywords: consensus; agreement; mechanism design; cognitive dissonance; reference-dependent preferences; collective choice; experiment.

\section{Introduction}

High levels of disagreement can be detrimental to the functioning of collective entities. Preference misalignment may undermine the effective implementation of a group's decisions and hinder a team's

*We would like to thank Enriqueta Aragonès, Federico Belotti, George Deltas, Antros Kourtellos, Clemens Puppe, Jana Rollman and audience members in Antigua Guatemala, Berlin, CREST, KIT, Montpellier, Thessaloniki and UAB for helpful comments and suggestions, as well as Georgios Voucharas for excellent research assistance. Financial support from the ANR-14-CE24-0007-01 (CoCoRICoCoDEC) grant is acknowledged by Matías Núñez and from the KOY $\Lambda$ TOYPABP-NE-0416-05 grant by Dimitrios Xefteris.

$\dagger$ Department of Economics, University of Cyprus, P.O. Box 20537, Nicosia 1678, Cyprus. email: louis.philippos@ucy.ac.cy

${ }^{\ddagger}$ CREST, CNRS, Ecole polytechnique, GENES, ENSAE Paris, Institut Polytechnique de Paris, 91120 Palaiseau, France. email: matias.nunez@ensae.fr

$\S$ Department of Economics, University of Cyprus, P.O. Box 20537, Nicosia 1678, Cyprus. email: xefteris.dimitrios@ucy.ac.cy 
performance in general. More importantly, it threatens the mere existence of the group: collective entities -families, teams, departments, corporations, or even countries- tend to break down when their members disagree substantially on important issues. Achieving higher levels of agreement within a group may therefore be seen as something desirable, if not vital. ${ }^{1}$

But how can one boost the level of agreement within a group? In this study we turn our attention to collective choice mechanisms and try to understand their role in this respect. The literature in economics typically assumes that individual preferences are stable over time and do not depend on past behavior or outcomes. That is, the traditional view is that collective choice procedures only aggregate individual preferences and do not affect them in any way. While convenient for analytical purposes, this assumption is unlikely to always hold. ${ }^{2}$ In fact, contrary to this assumption, scholars that study group decision making in organizations suggest that the process through which decisions are made, and the way individuals behave during such process, may have an important influence on the group members' attitudes and beliefs. ${ }^{3}$ In particular, they find that group decision making based on consensus can turn participants more favorable to the group's decision, a view shared by some practitioners as well. ${ }^{4}$ Ultimately, whether particular collective choice mechanisms can foster agreement is an empirical question, the answer to which we seek in this paper.

It is critical for our research to have a clear definition of agreement in the context of collective choice. In particular, we need to clarify the differences between actual agreement (i.e. the similarity of actual individual preferences) and manifest support for an outcome (i.e. the individuals' support for an outcome as manifested during a collective choice process). ${ }^{5}$ During decision making, group members are given the opportunity to express their degree of support for possible outcomes. The exact way this is done varies: they can make proposals, accept or reject them, cast a veto against them, vote in favor or against different alternatives, rank them, approve a number of them, abstain, etc. A high level of manifest support for an outcome may be observed (e.g. a unanimous vote in favor of a proposal) without precluding substantial levels of actual disagreement remaining. Importantly, not all mechanisms provide

\footnotetext{
${ }^{1}$ See De Dreu and Weingart (2003) and De Wit et al. (2012).

${ }^{2}$ See Becker (1993), Aaron (1994) and Bowles (1998) for important discourses related to this issue.

${ }^{3}$ See Schweiger et al. (1986, 1989), Priem et al. (1995) and Hartnett (2011)

${ }^{4}$ For example, the Bureau of Land Management National Natural Resources Policy for Collaborative Stakeholder Engagement and Appropriate Dispute Resolution states: "agreements reached using [consensus-oriented processes] can be more creative, satisfying, and enduring than those imposed through conventional systems of conflict resolution". And according to the Internet Engineering Task Force Working Group Guidelines and Procedures: "the core rule for operation is that acceptance or agreement is achieved via working group 'rough consensus'."

${ }^{5}$ See Kelman (1958), Priem et al. (1995) and Kellermanns et al. (2005) for detailed discussions of this distinction.
} 
incentives for consensual behavior (i.e. for high levels of manifest support for the outcome). In some cases, it is in one's best interest to exaggerate her disagreement with a specific outcome in order to move the final outcome closer to what she deems optimal. In other cases, individuals can reap higher benefits by being more accommodating. The closer a mechanism is to the latter type, the more congruent we say it is.

The main hypothesis we want to test in this paper is whether congruent collective choice mechanisms -procedures that promote consensual behavior- lead to higher levels of post-decision actual agreement, compared to incongruent ones - procedures that incentivize individuals to stress and exaggerate their differences. If our hypothesis is true, then designing and using congruent mechanisms can help groups enter a "virtuous circle of agreement": by incentivizing consensual behavior, we push towards higher levels of preference homogeneity.

We see two potential channels through which a mechanism's congruency can have an effect on preferences: one self- and one other-regarding. In the first case, an aversion for dissonance between actions and attitudes is in operation: the more a voter has supported a particular outcome, the more she ends up "liking" said outcome. ${ }^{6}$ Here it is a voter's own manifest support for the outcome that influences preferences. In the second case a voter considers the other group members' support for the outcome. What is assumed is that voters have other-regarding preferences and care for others' payoffs. $^{7}$ If this is true and a voter interprets others' support for an outcome as a signal that this is close to their true preferences, then this can make her more positively inclined towards the outcome. ${ }^{8}$ Both these channels lead to the same result: higher manifest support for the outcome, either one's own or that of others, move voters' preferences closer to the outcome and, therefore, closer together. One way of looking at this is as preferences being reference-dependent: individuals, after participating in a collective choice process, become more favorable to the outcome of the process, i.e. the outcome has an attractor effect on their preferences. The strength of the effect depends on the level of congruency of the collective choice mechanism used. This is the theoretical framework based on which we examine our hypothesis

\footnotetext{
${ }^{6}$ Aversion to dissonance between choices and attitudes is well established by social psychologists (Festinger, 1962, 1964; Bandura et al., 1991). Indeed, the need of subjects to be consistent does not imply only that actions align with existing preferences, but also that preferences may adapt to harmonize with past actions (Insko and Schopler, 1967). For applications of this theory in voting one is referred to Beasley and Joslyn (2001); Mullainathan and Washington (2009); Acharya et al. (2018). Kamenica (2012) also discusses this from the perspective of behavioral economics.

${ }^{7}$ See Fehr and Schmidt (1999), Bolton and Ockenfels (2000), and Charness and Rabin (2002) for examples of such preferences.

${ }^{8}$ Notice that while this reasoning requires individuals to (perhaps mistakenly) interpret manifest support as an indication of preference for a specific outcome, if everyone's post-outcome preferences are formed in the same way, these naively formed beliefs about others' preferences turn out to be moving in the right direction.
} 
empirically.

A major problem with trying to answer these questions in natural settings is the heterogeneity of collective choice frameworks. Indeed, different mechanisms apply to different problems, and even those that are used in similar contexts rarely involve groups with similar preferences or produce similar outcomes. ${ }^{9}$ Unless the cases in which a congruent and an incongruent mechanism apply are directly comparable, identification of the effect of the mechanisms on post-decision actual agreement becomes difficult. Indeed, if two decision-making settings are very disparate in terms of the number and quality of the alternatives, the initial preferences and the procedural details, then, even if one observes heterogeneous levels of post-decision actual agreement, it is impossible to attribute this difference exclusively to the collective choice mechanisms. Therefore, to pin down the role of decision making procedures on preference cohesion, we need to turn to the controlled environment of the experimental lab.

Overcoming the problems described above, even in the laboratory, is not easy. To deal with them we conduct a theory-driven laboratory experiment, exploiting classic (Moulin, 1980) and more recent (Yamamura and Kawasaki, 2013; Núñez and Xefteris, 2017) findings regarding mechanism design in the single-peaked context. In particular, we compare subjects' behavior under two decision mechanisms -the Median Approval and the Simple Mean- in the same collective choice problem - the selection of a point in the unit interval. In theory, these two rules are outcome-wise identical: For any given preference profile, they result in the same unique Nash equilibrium outcome. At the same time, they largely differ in the incentives for manifest support for the outcome. The Median Approval rule allows each individual to support any range of alternatives (i.e. give one vote to as many alternatives as she wants) and the outcome coincides with the median of the distribution of the votes cast by all voters. Since players have single-peaked preferences (i.e. each voter is characterized by an ideal policy and prefers that the outcome is as close as possible to her ideal policy), incentives are such that in equilibrium the implemented policy is included in all individuals' sets of approved alternatives: everyone appears to be supporting the outcome. According to the Simple Mean rule, each individual reports a number, and the outcome coincides with the mean of the reports. The incentives lead individuals to vote for extreme alternatives. In equilibrium, this gives rise to an exaggerated disagreement between individual votes and the implemented policy. Thus, the Median Approval is a congruent mechanism and the Simple Mean an incongruent one. ${ }^{10}$ However, they both apply to the same class of problems, and, more importantly,

\footnotetext{
${ }^{9}$ For example, all decision rules in Schweiger et al. (1986) and similar studies typically lead to different resolutions.

${ }^{10}$ Notice that this difference of the two mechanisms is reminiscent of -but not equivalent to- the diverging collusion
} 
they produce identical equilibrium outcomes.

After the experimental subjects make a collective decision under one of these two mechanisms (in Part A), they move to a random dictatorship phase (in Part B), where each of them is allowed to propose a revision of the original decision, and each of the proposals gets implemented equiprobably. In this manner, we elicit the individuals' preferences after the collective choice is made. This allows us to gauge the level of agreement within a group. Since we can control for initial preferences, any differences in final preferences that we observe between the Median Approval and the Simple Mean treatment should be attributed to the mechanisms and the way individuals behave in each one of them. Moreover, since both mechanisms deliver similar outcomes, a potential difference in post-decision levels of actual agreement should be, mainly, due to factors that are not related to the outcome itself or to initial preferences.

In Part A we find that the outcomes of the Median Approval and the Simple Mean treatment are very close to what is predicted by theory and conditional on the group's preference profile, the two mechanisms implement, on average, very similar outcomes. Additionally, the manifest support for the winning alternative is much larger under the Median Approval treatment than under the Simple Mean treatment. For instance, in about $80 \%$ of the cases a subject voted for the implemented alternative in the Median Approval treatment, while in the Simple Mean treatment individual votes were substantially far from the outcome: on average one-third of the total measure of the alternatives' space. In Part B, we compare the level of ex-post agreement in the two treatments by measuring the dispersion of withingroup proposals. For both treatments we find that dispersion is smaller than that of the exogenously given payoff-maximizing points; a proxy for ex-ante disagreement. But the reduction in dispersion is double in size in the Median Approval treatment compared to the Simple Mean one. In other words, we find that following a decision made using a more congruent mechanism, groups exhibit higher levels of actual agreement. Importantly, this large difference is statistically significant at any conventional level.

To be sure, while Part A outcomes are similar across treatments, they are not identical. For instance, the Simple Mean treatment generates slightly higher inequality in payoffs compared to the Median Approval. Hence, one cannot rule out additional outcome-related mechanisms that might be responsible for part of the treatment effect. We conduct several robustness checks which reassure us that even if incentives provided by games of strategic complements and games of strategic substitutes (see, e.g., Potters and Suetens, 2009). In a game of strategic complements (substitutes), a switch of the strategy of a player, incentivizes the other player to move in the same (opposite) direction, leading to more (less) collusive outcomes. Similarly, under a congruent decision mechanism, players have incentives to "approach" one another, while under a non-congruent mechanism they have incentives to divide and move towards the extremes. 
such channels exist, they are not sufficient to explain the differences between treatments. For instance, by focusing only on the subset of cases in which the two rules delivered extremely similar outcomes we still find the same difference in post-decision agreement across treatments.

After finding strong empirical evidence backing our main hypothesis we take a closer look at the data to see whether our rationale for why this happens is also supported. In line with our simple framework for how preferences change, we find that under both the Median Approval and the Simple Mean treatment the proposal of a subject is, essentially, a convex combination of her ideal policy and the original group decision. That is, we find that individuals incorporate the outcome of a collective decision process into their own utility function. It then operates as a common attractor for all group members preferences, bringing them closer together. Importantly, this effect has different magnitudes in the two mechanisms: the weight assigned to the original decision is about $26 \%$ in the Median Approval treatment and only about 5\% in the Simple Mean treatment.

As a next step we test whether manifest support for the outcome can explain the treatment effect. We find that a voter's own manifest support for the outcome has important across- and within-treatment explanatory power. In contrast, other's manifest support does not seem to interact with the attractor effect. Hence, we provide evidence that not only supports the idea that congruent mechanisms move a group members' preferences closer together, but additionally, that own manifest support for an outcome - even as it varies within the context of particular mechanism- plays a part in explaining the change in own preferences.

In what follows we discuss the relevant literature (section 2), provide a discussion regarding the two decision rules (section 3), detail our experimental design (section 4), present our results (section 5) and conclude (section 6).

\section{Relevant Literature}

There has been a growing interest in the use of laboratory experiments to measure the effects of different collective decision processes on the effectiveness or acceptance of decision outcomes. Walker et al. (2000) show that voting can increase efficiency through coordination in a common pool resource game. Dal Bó et al. (2010) illustrate that the effects of a policy on cooperation are stronger when it is chosen democratically. A similar effect is found for the performance of sanctioning institutions in public good games that are voted on instead of imposed exogenously (Tyran and Feld, 2006; Sutter et al., 2010; 
Markussen et al., 2013; Kamei et al., 2015; Kamei, 2016) or chosen by an elected -versus imposedleader (Grossman and Baldassarri, 2012). In contrast to the above, Markussen et al. (2014) find that the effectiveness of a scheme of intragroup competition is not affected by whether or not it is chosen democratically. Beyond social dilemmas, Mellizo et al. (2014) find that democratic processes can lead to higher effort in the workplace when compensation schemes are chosen by voting. As we measure the effect of the group choice process directly on group members' preferences concerning the outcome, our results can help explain this typically positive effect of democratic institutions.

With the exception of Walker et al. (2000), these papers compare exogenous to endogenous choice. By contrast, since we focus on the apparent consensus on an outcome, the processes we compare are all endogenous. Furthermore, our design allows us to experimentally control for differences in the outcomes produced by different mechanisms, giving a clean identification of the effect of a given mechanism on individuals' preferences. Previous work typically controls for such effects only econometrically.

Scholars in both management and psychology have long been interested in the effect of different decision processes on group decisions (see, for instance, Mason and Mitroff, 1981; Schweiger et al., 1986, 1989; Priem et al., 1995; Hartnett, 2011). Another long stream of literature in organizational studies examines the role of conflict in teams and groups. Two extensive meta-studies (De Dreu and Weingart, 2003; De Wit et al., 2012) find that conflict is in general negatively correlated with group performance, as measured by different metrics. While there is some support for the idea that conflict can be beneficial in specific contexts (Jehn, 1994; Jehn et al., 1997; Jehn and Mannix, 2001), this is not universally true for the relationship between conflict and group satisfaction. Our work complements this literature by looking at conflict that is created -or mitigated- by the decision processes used. We do not measure the effect of disagreement on the outcome; in fact we use a design that minimizes any possibility for such an effect. This allows us to obtain estimates of the causal effects of manifest support for an outcome on the ex-post levels of actual agreement in a group. To our knowledge, such an incentivized elicitation of ex-post preferences has not been applied in this literature.

Our results can be interpreted as evidence for procedural utility: Processes matter above and beyond their explicitly associated outcomes. The idea has its origins in social psychology (Thibaut and Walker, 1975; Lind and Tyler, 1988), but it has also been advanced by economists (Sen, 1997; Frey et al., 2004; Frey and Stutzer, 2005). Research in this area focuses mainly on moral characterizations of processes, such as whether participants are treated equally or fairly, and the effect the moral characterization of 
a process may have on outcomes and their acceptance. In our case, we look at processes that, while resulting in divergent levels of apparent consensus, can arguably not be ranked in terms of how fair they are. Hence, the effect of procedures on preferences in our case is independent of procedural justice.

Another closely related line of research studies how other-regarding preferences (Fehr and Schmidt, 1999; Bolton and Ockenfels, 2000; Charness and Rabin, 2002) or reciprocity (Rabin, 1993; Levine, 1998; Falk and Fischbacher, 2006; Dufwenberg and Kirchsteiger, 2004) can explain deviations from selfinterested behavior. Contrary to our expectations, we do not find other-regarding preferences to be explaining much of the behavior we observe in our experiment. Similarly for reciprocity, although there is no obvious way in which subjects' choices can be classified as (un)kind or reciprocal. Hence we cannot preclude that subjects exhibit some form of reciprocity that we cannot detect. Still, it does not seem to be the main factor determining our results.

Our finding that an individual's support for an outcome, as expressed through her vote, moves her ideal policy closer to said outcome seems to be parallel with what Corazzini et al. (2014) find. Their paper looks at how the process of electing leaders may incentivize them to keep their promises. This of course relates to the literature on lying aversion (Gneezy, 2005; Fischbacher and Föllmi-Heusi, 2013). In our experiment subjects are not aware when voting that they will have an opportunity to propose a new outcome. Hence, their post-outcome behavior seems to reveal a desire for self-consistency or selfconcept maintenance (Mazar et al., 2008) and avoidance to dissonance between choices and preferences (Festinger, 1962, 1964; Insko and Schopler, 1967; Bandura et al., 1991).

To properly choose the decision context and the employed mechanisms, one has to turn to the theoretical literature. We have chosen to focus on the single-peaked domain since: a) it is quite intuitive and easy to explain in the lab, and b) it is the only one, to our knowledge, for which outcome-wise identical congruent and incongruent mechanisms exist. One the one hand, Renault and Trannoy (2005) and Yamamura and Kawasaki (2013) analyze the properties of the Simple Mean mechanism and show that the unique Nash equilibrium outcome under the average voting rule must be equivalent to the median of $\left(h_{1}, h_{2}, \ldots, h_{n}, \frac{1}{n}, \frac{2}{n}, \ldots, \frac{n-1}{n}\right)$, where $h_{i}$ is player $i$ 's ideal policy. They also prove that in equilibrium most players select an extreme announcement (hence, the Simple Mean mechanism is incongruent). On the other hand, Núñez and Xefteris (2017) show how to implement the same outcome using the Median Approval mechanism that leads players to endorse the implemented alternative (hence, the Median Approval mechanism is congruent). Finally, Gershkov et al. (2017) establish that the same decisions 
can be made through sequential quota procedures. A study of the comparative effects of simultaneous versus sequential mechanisms is beyond the scope of this analysis, but it presents itself as an interesting avenue of research for the future.

\section{Theory}

\subsection{A simple framework}

A group of $N$ members chooses a point $x$ in a compact policy space $\mathcal{P} \subset \mathbb{R}$. The group makes a decision using some mechanism $M$ that asks voters to signal their preferences and produces an outcome, $x \in \mathcal{P}$, based on these messages. We denote a voter's submitted message by $b_{i}$, but the exact form of this message depends on the mechanism used. ${ }^{11}$

We assume that preferences are single-peaked and we focus on each voter's preferred policy $h_{i}^{t} \in \mathcal{P}$. The time superscript $t \in\{0,1\}$ indicates that preferences are allowed to be different before a collective choice is made $(t=0)$ and after $(t=1)$. What we are interested in is the group's actual agreement level, which can be captured by a measure of dispersion of voters' preferred policies. Let $S: \mathcal{P}^{N} \rightarrow \mathbb{R}$ be such a measure. The lower the dispersion, the higher the agreement.

Our main hypothesis is that the post-decision levels of agreement will be different depending on the mechanism used to reach the decision. In particular, congruent mechanisms with higher levels of manifest support for an outcome will lead to higher levels of actual agreement. To better understand the process that can lead to such a result we develop a simple framework for how preferences are affected by the outcome in our context. ${ }^{12}$

Our intuition is that the outcome of the group decision making process may act as an attractor for post-decision individual preferences, mitigating the role of initial preferences. We formalize this in a simple way by assuming that the post-outcome ideal policy of voter $i$ is a weighted average of the outcome and her original ideal policy, with corresponding weights $\beta \in[0,1]$ and $1-\beta$. That is, the post-decision ideal policy of voter $i$ can be written as:

$$
h_{i}^{1}=\beta \cdot x+(1-\beta) \cdot h_{i}^{0} .
$$

\footnotetext{
${ }^{11}$ In the two mechanisms we use in the experiment and that are described in the next section, $b_{i}$ is a subset of the policy space. For one of the two mechanisms $b_{i}$ is restricted to be a singleton.

${ }^{12}$ This simple framework is reminiscent of models for reference-dependent preferences, although in our case it lacks the deeper elements and micro-foundations found there. Even so, it goes a long way in formalizing our intuition and forming a basis for testing our theory.
} 
It follows immediately from the above formulation that any $\beta>0$ implies a smaller dispersion of post-decision ideal policies, i.e. a higher level of actual agreement, compared to the initial one. In fact, the stronger the attractor effect (i.e. the higher the $\beta$ ), the higher the post-outcome levels of agreement.

We conjecture that the strength of the attractor effect depends on the type of mechanism used to reach the collective outcome. In particular, we believe that mechanisms in which incentives are such that participants end up manifesting higher levels of support for the collective choice made, will also lead to higher values for $\beta$. This conjecture stems from our reading of the management literature where analysis is often done using group level variables. ${ }^{13}$ While a mechanism may induce higher levels of manifest support for an outcome to group members, it is not clear whether the strengthening of the attractor effect for an individual should happen because of its own higher support or that of others. The support of others in a group for a specific outcome could be interpreted by some as a preference for said outcome. Hence, individuals exhibiting other-regarding preferences may move their own ideal-policy closer to that. ${ }^{14}$ On the other hand, existing literature in psychology has established that individuals exhibit a strong aversion for dissonance between their actions and their attitudes towards objects of interest. ${ }^{15}$ To resolve this tension, individuals not only choose actions that are compatible with their current attitudes, but, importantly, also revise their attitudes to make them consonant with past behavior.

Let us assume that

$$
c_{i}=c\left(x, b_{i}\right)
$$

is a measure that captures the compatibility between a voter's message, $b_{i}$, and the group outcome, $x$. We call this an individual's manifest support for the outcome. For example, consider the case where the mechanism requires messages $b_{i} \subseteq \mathcal{P}$, as is the case in all our experimental treatments. Let $A, B>0$, and $d: \mathcal{B} \times \mathcal{P} \rightarrow[0, A]$ be a distance metric between a subset and a point from the policy space. Then:

$$
c\left(x, b_{i}\right)=\left(A-d\left(b_{i}, x\right)\right) \cdot B
$$

gives a family of measures for manifest support. ${ }^{16}$

\footnotetext{
${ }^{13}$ See Mason and Mitroff (1981); Schweiger et al. (1986, 1989); Priem et al. (1995); Hartnett (2011) and the relevant discussion in the previous section.

${ }^{14}$ See Fehr and Schmidt (1999), Bolton and Ockenfels (2000), and Charness and Rabin (2002) for examples of such preferences.

${ }^{15}$ See, e.g., Festinger (1962, 1964); Insko and Schopler (1967); Bandura et al. (1991). For applications of this theory in voting one is referred to Beasley and Joslyn (2001); Mullainathan and Washington (2009); Acharya et al. (2018)

${ }^{16}$ For our empirical analysis we will specifically consider the distance between $x$ and $b_{i}$ 's closest point from $x$, i.e. $d\left(b_{i}, x\right)=\min \left\{|v-x|\right.$, s.t. $\left.v \in b_{i}\right\}$.
} 
Also,

$$
C_{i}=g\left(c_{-i}\right)
$$

is a measure of other group members' manifest support for a decision, as viewed by voter $i$ (obviously we assume $\frac{\partial g}{\partial c_{j}}>0, j \neq i$ ). Setting $C_{i}=\frac{1}{N-1} \sum_{j \neq i} c_{j}$ gives an example of such a measure. Our conjecture as discussed above then takes two forms that can be formalized as follows

$$
\frac{\partial \beta_{i}}{\partial c_{i}}>0
$$

and

$$
\frac{\partial \beta_{i}}{\partial C_{i}}>0
$$

If either of the above holds true, then our "virtuous-cycle" hypothesis follows. When the manifest support for the outcome is higher, all voters' ideal policies move closer to the outcome and, hence, closer to each other:

$$
\frac{\partial S\left(h^{1}\right)}{\partial c_{i}}<0, \forall i
$$

In our experiment we test the above theory by allowing groups to make decisions using different mechanisms and eliciting post-outcome preferences. To do so we need to overcome an obvious endogeneity problem. Post-decision preferences, as seen in (1) depend on initial preferences $h_{i}^{0}$, on the outcome $x$ and on the size of the attractor effect $\beta$. But according to our conjecture, $\beta$ depends on $c_{i}$, which is in turn affected by the outcome $x$ and the behaviors $b$, as seen in (2), (5) and (6). Furthermore, it is possible for $\beta$ to be affected by $x$ in a more direct way, independently of the group members' voting behavior. ${ }^{17}$ It is straightforward to control for initial preferences in the lab and we do so. But if different mechanisms lead to different outcomes $x$, then it is not always possible to identify whether the attractor effect is affected by manifest support for the outcome, or, more generally, whether the use of different mechanisms has any effect on post-decision preferences that is independent from the outcome.

One way to overcome this is by finding specific mechanisms that, given the initial preferences, lead to the same outcome $x$ but with different behavior $b$. In particular, behavior should differ in such a way that we observe higher levels of manifest support for the outcome in one mechanism compared to

\footnotetext{
${ }^{17}$ This could be the result of preferences based on procedural justice, e.g. Sen (1997); Frey et al. (2004). For instance individuals' preferences may move closer to the outcome if they feel it was a fair decision.
} 
another. More formally, the two mechanisms $M$ and $M^{\prime}$ need to satisfy:

$$
x^{*}\left(h^{0}, M\right)=x^{*}\left(h^{0}, M^{\prime}\right)
$$

and

$$
c_{i}\left(x^{*}\left(h^{0}, M\right), b_{i}^{*}(M)\right) \geq c_{i}\left(x^{*}\left(h^{0}, M^{\prime}\right), b_{i}^{*}\left(M^{\prime}\right)\right), \forall i
$$

where $x^{*}$ denotes the equilibrium outcome and $b^{*}$ the corresponding equilibrium behaviors. In the next subsection we present two mechanisms that conform with these desiderata and form the basis of our experimental design.

\subsection{Two Alternative Mechanisms}

With respect to the group decision in the first stage of the game, we focus on two mechanisms: the Simple Mean mechanism and the Median Approval mechanism. This section reviews their definitions and the equilibrium prediction for the situation tested experimentally. For a formal derivation of these results, we refer the reader to Renault and Trannoy (2005) and Yamamura and Kawasaki (2013) for the Simple Mean mechanism, and to Núñez and Xefteris (2017) for the Median Approval mechanism.

We consider a committee with three individuals (i.e. $n=3$ ); a decision $x \in[0,100]$ needs to be made.

Individual preferences over outcomes are summarized by the utility function $-\left|x-h_{i}^{0}\right|$. Individual utility is maximized at $x=h_{i}^{0}$ (i.e. at the individual's preferred decision). The larger the difference between the decision $x$ and $h_{i}^{0}$, the smaller the individual utility. Our arguments do not depend on the precise shape of the utility functions and extend as long as individual preferences have a unique preferred decision (i.e. single-peaked preferences).

In order to ease the comparison, we focus on the case with $h_{1}^{0}<h_{2}^{0}<h_{3}^{0}$ with $h_{1}^{0} \leq \frac{200}{3}$ and $h_{3}^{0} \geq \frac{100}{3}$. As we show below, in this case, both mechanisms under consideration admit a unique equilibrium outcome and a simple derivation of the equilibrium strategies.

Simple Mean mechanism: Each player $i \in N$ simultaneously submits a value $b_{i} \in[0,100]$. For each vector of announcements $b=\left(b_{1}, b_{2}, b_{3}\right)$, the outcome $\theta_{\mathbf{S M}}(b)$ equals:

$$
\theta_{\mathbf{S M}}(b)=\frac{b_{1}+b_{2}+b_{3}}{3}
$$

Equilibrium Behavior: In equilibrium, each player casts a strategy that minimizes the distance 
between the outcome $\theta_{\mathbf{S M}}(b)$ and her own peak. Player 1, the player with the lowest peak, always announces 0 since she anticipates that the outcome is higher than her peak and wants to shift the outcome as much as possible to the left. Similarly, Player 3, the player with the highest peak, always announces 100 since she wants to shift the outcome as much as possible to the right.

The strategy of the median player, Player 2, depends on the value of her type $h_{2}^{0}$. If the median type is low $\left(h_{2}^{0} \leq \frac{100}{3}\right)$, then Player 2 announces 0 and, by symmetry, if the median type is high (i.e. if $\left.h_{2}^{0} \geq \frac{200}{3}\right)$, then Player 2 announces 100. Finally, if the median peak is centered $\left(\frac{100}{3} \leq h_{2}^{0} \leq \frac{200}{3}\right)$, the median player plays a strategy that allows to obtain $h_{2}^{0}$ as an outcome: This strategy equals $3 h_{2}^{0}-100$.

In any equilibrium, the outcome is equal to $f\left(h_{1}^{0}, h_{2}^{0}, h_{3}^{0}\right)=\operatorname{median}\left(h_{1}^{0}, \frac{100}{3}, h_{2}^{0}, \frac{200}{3}, h_{3}^{0}\right)$. The equilibrium is unique since slightly altering one's announcement affects the final outcome independently of the announcement of the rest of the players (see Proposition 3 in Yamamura and Kawasaki, 2013, for a precise statement of the conditions that lead to a unique equilibrium) .

Median Approval mechanism: Each player $i \in N$ simultaneously submits an interval $b_{i}=\left[b_{i}^{-}, b_{i}^{+}\right]$ with $b_{i}^{-} \leq b_{i}^{+}$. Player $i \in N$ casts one vote for each alternative included in her chosen interval. Let $\mu\left(b_{i}\right)=$ $b_{i}^{+}-b_{i}^{-}$denote the measure of $b_{i}$ and, for each set of intervals $b=\left(b_{1}, b_{2}, b_{3}\right), \mu(b)=\mu\left(b_{1}\right)+\mu\left(b_{2}\right)+\mu\left(b_{3}\right)$ the measure of $b$. For each $x \in[0,100]$ and each set $b, s_{x}(b)=\#\left\{i \in N \mid x \in b_{i}\right\}$ denotes the score of $x$ at $b$. Note that if $\mu(b)=0$, each announcement is a singleton. If $\mu(b)>0$, the distribution of votes $\phi: \mathcal{B}^{n} \times[0,100]$ is denoted by $\phi(b, z)=\frac{1}{\mu(b)} \int_{0}^{z} s_{x}(b) d x$.

For each vector of announcements $b=\left(b_{1}, b_{2}, b_{3}\right)$, the outcome $\theta_{\mathbf{M A}}(b)$ equals:

$$
\theta_{\mathbf{M A}}(b)= \begin{cases}\operatorname{median}\left(b_{1}, b_{2}, b_{3}\right), & \text { if } \mu(b)=0 \\ \max \left\{z^{*} \in[0,100] \mid \phi\left(b, z^{*}\right)=\frac{1}{2}\right\}, & \text { otherwise }\end{cases}
$$

Figure 1 depicts the computation of the median of the announced intervals. After plotting the intervals (Figure 1b), we plot the vote distribution (Figure 1c) -that is, the number of votes that each alternative obtains. The median of the intervals coincides with the point that divides the area below the vote distribution into two equal parts.

Equilibrium Behavior. In a similar fashion to the Simple Mean mechanism, each player chooses a strategy that minimizes the distance between the outcome and her own peak. The unique equilibrium outcome is also equal to $f\left(h_{1}^{0}, h_{2}^{0}, h_{3}^{0}\right)=\operatorname{median}\left(h_{1}^{0}, \frac{100}{3}, h_{2}^{0}, \frac{200}{3}, h_{3}^{0}\right)$.

Player 1 announces an interval $b_{1}$ that ranges from 0 to $f\left(h_{1}^{0}, h_{2}^{0}, h_{3}^{0}\right)$. Namely, she votes for the 


\begin{tabular}{|c|c|c|}
\hline Announcements & $b_{i}^{-}$ & $b_{i}^{+}$ \\
\hline Individual 1 & 0 & 40 \\
\hline Individual 2 & 30 & 50 \\
\hline Individual 3 & 30 & 90 \\
\hline
\end{tabular}

(a) Individuals report intervals.

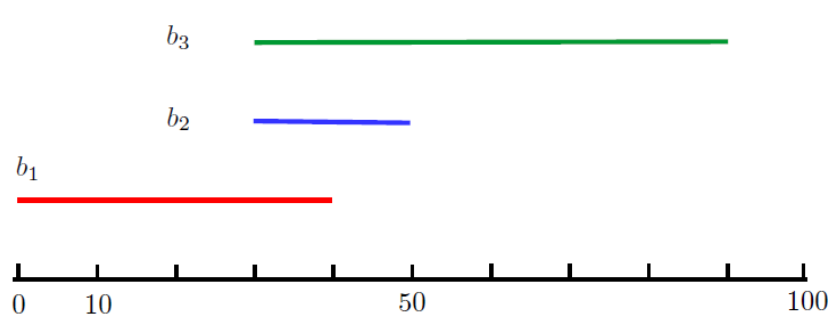

(b) Graphic representation of the intervals.

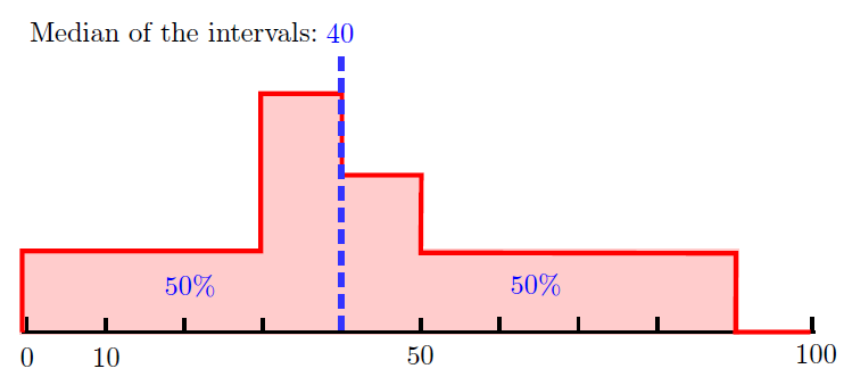

(c) Distribution generated by the intervals.

Figure 1: Computing the median of the intervals.

outcome $f\left(h_{1}^{0}, h_{2}^{0}, h_{3}^{0}\right)$ and for any alternative located to its left. By symmetry, Player 3 approves the interval $b_{3}$ that goes from $f\left(h_{1}^{0}, h_{2}^{0}, h_{3}^{0}\right)$ until 100, voting for that outcome and all the alternatives located to its right.

The median player, Player 2, plays a strategy that depends on the value of $h_{2}^{0}$. When $h_{2}^{0}<\frac{100}{3}$ $\left(h_{2}^{0}>\frac{100}{3}\right)$ then she votes for $b_{2}=\left[0, \frac{100}{3}\right]\left(b_{2}=\left[\frac{200}{3}, 100\right]\right)$, and the outcome is equal to $\theta_{\mathbf{M A}}=\frac{100}{3}$ $\left(\theta_{\text {MA }}=\frac{200}{3}\right)$. When $\frac{100}{3} \leq h_{2}^{0} \leq 50\left(50 \leq h_{2}^{0} \leq \frac{200}{3}\right)$, she can vote any alternative from 0 to $4 h_{2}^{0}-100$ (from $4 h_{2}^{0}-200$ to 100 ) -that is, also $h_{2}^{0}$ - inducing the implementation of her ideal policy.

To better understand the equilibrium behavior, consider an example with $h_{1}^{0}<h_{2}^{0}=40<h_{3}^{0}$ and the strategy profile $b_{1}=[0,40], b_{2}=[0,60]$ and $b_{3}=[40,100]$. These strategies lead to the implementation of alternative $40-$ which is voted by all players - since in total $40+60+60=160$ units of votes are cast, and half of them are given to alternatives to the left (right) of 40. To see why this is an equilibrium consider deviations of the first player. If, for example, she expands her interval to $b_{1}^{\prime}=[0,46]$, then the total votes cast will be $46+60+60=166$, and the implemented alternative will thus move from 40 to 41 . Since $h_{1}^{0}<h_{2}^{0}=40$, this is not a profitable change for player 1 . If she shrinks her interval to $b_{1}^{\prime \prime}=[0,20]$, then the total votes cast will be $20+60+60=140$, and the implemented alternative will thus move from 40 to 45 . Since $h_{1}^{0}<h_{2}^{0}=40$ again this is not a profitable deviation. Of course, these deviations are just indicative of what may happen: Players have a variety of different options to choose from. These few cases though are sufficient to show that both by voting for alternatives to the right of the implemented 
outcome and by not voting for alternatives to the left of the implemented alternative, a player can shift the outcome to the right. Hence, if a players's ideal policy is to the left, her only best response is to vote for the outcome and all alternatives to its left.

Figure 2 depicts the equilibrium outcome, which is the same in both mechanisms for a given set of peaks. In particular, it is the median of the peaks $h_{1}^{0}, h_{2}^{0}, h_{3}^{0}$ jointly with $\frac{100}{3}$ and $\frac{200}{3}$. Since we restrict the peaks of the extreme voters to be $h_{1}^{0} \leq \frac{200}{3}$ and $h_{3}^{0} \geq \frac{100}{3}$, one can graph it as a function of the peak of the median, $h_{2}^{0}$.

\section{Equilibrium outcome}

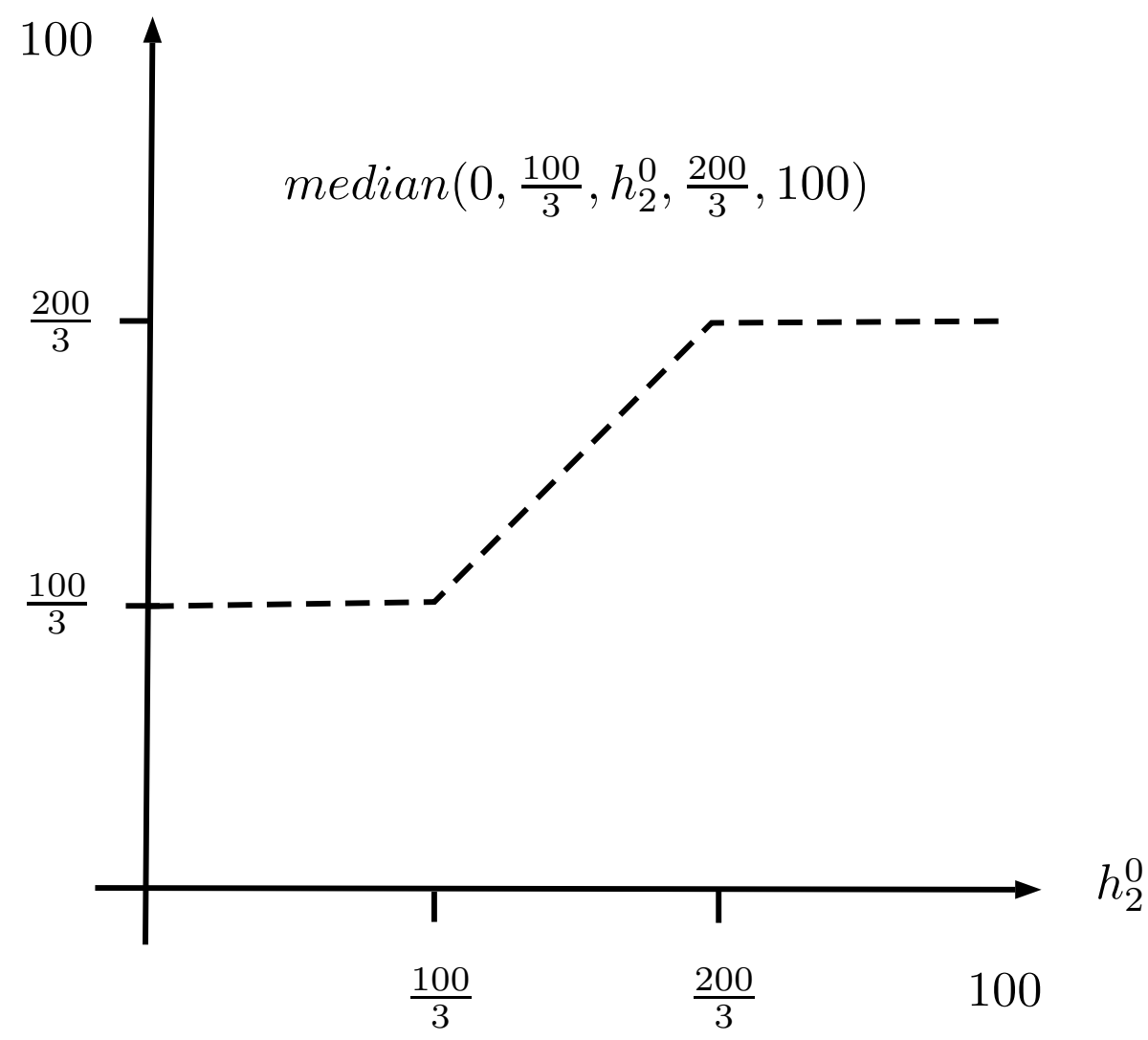

Figure 2: Equilibrium outcome as a function of $h_{2}^{0}$ with $h_{1}^{0} \leq \frac{200}{3}$ and $h_{3}^{0} \geq \frac{100}{3}$.

\subsection{A Mechanism for Second-Stage Decisions}

For second-stage decision making we employ the random dictatorship mechanism. According to this mechanism each individual proposes an outcome and each of these proposals is selected as the secondstage group decision with probability one third. Notice that this mechanism is strategy-proof and 
admits a unique equilibrium. In this unique equilibrium each individual $i$ reports truthfully her preferred decision $h_{i}^{1}$.

\section{Experimental Design and hypotheses}

\subsection{Design}

The experimental design is geared towards answering our main question on the influence of collective decision mechanisms on actual agreement. For this, we use a between-subject design with two treatments, each of which has two parts. In the first part, subjects make collective decisions using one of the two mechanisms described in the previous section, a different one in each treatment. The decision rules are such that theory predicts the same outcome with different levels of manifest support. Payoffs in the first part depend on this outcome. In the second part subjects make individual proposals, one of which is chosen randomly for each group. Payoffs in this part are determined by the randomly selected proposal in each group. We now explain the details of the experiment and our design choices.

The experiment took place at the University of Cyprus Lab of Experimental Economics (UCY LExEcon). A total of 180 subjects, all students of the University of Cyprus, participated in 12 equally sized sessions, with 6 sessions per treatment. ${ }^{18}$ Recruitment was done using ORSEE (Greiner, 2015). The experiment was computerized, and the software was programmed and run using zTree (Fischbacher, 2007). An outline of the design is presented in Table 1.

Timing For both treatments, subjects received written instructions for Part A after entering the lab. ${ }^{19}$ These were also read aloud to establish common knowledge. After Part A finished, instructions for Part B were distributed and read aloud. At the end of Part B, subjects were informed about their profits and paid privately before leaving the lab. Thus, while in Part A subjects knew there will be a second part to the experiment, they were entirely unaware of the experimental task in Part B or if and how it was connected to the task in Part A.

\footnotetext{
${ }^{18}$ Two pilot sessions were completed before the main experiment to finalize the design, fine-tune some of the parameters, and receive feedback on the instructions. Data from these pilot sessions are not included in any of our analysis. A first version of this paper was circulated with data from the first six sessions. Following suggestions by referees we conducted six additional sessions using the same parameters to enlarge our dataset. There was no qualitative change in our results.

${ }^{19} \mathrm{~A}$ translation of the instructions, originally in Greek, can be found in the Appendix.
} 


\begin{tabular}{|c|c|c|c|c|c|c|}
\hline Treatment & $\begin{array}{c}\text { Part } A \\
\text { (20 periods) }\end{array}$ & $\begin{array}{c}\text { Part B } \\
\text { (20 periods) }\end{array}$ & $\mathrm{N}$ & $\begin{array}{c}\text { \# of } \\
\text { Sessions }\end{array}$ & $\begin{array}{l}\text { Subjects } \\
\text { per } \\
\text { session }\end{array}$ & $\begin{array}{l}\text { Group } \\
\text { size }\end{array}$ \\
\hline MA & $\begin{array}{l}\text { Interval } \\
\text { voting with median } \\
\text { as outcome }\end{array}$ & $\begin{array}{l}\text { Random } \\
\text { dictator } \\
\text { game }\end{array}$ & 90 & 6 & 15 & 3 \\
\hline SM & $\begin{array}{l}\text { Single vote } \\
\text { with mean } \\
\text { as outcome }\end{array}$ & $\begin{array}{l}\text { Random } \\
\text { dictator } \\
\text { game }\end{array}$ & 90 & 6 & 15 & 3 \\
\hline
\end{tabular}

Collective choice - Part A In each round of Part A, subjects are placed in groups of three. Each group needs to choose collectively an integer between 1 and 100 as the group's destination. Each group member has an individual starting point, that is, a different integer between 1 and 100. The payoff in each period is then 100 points minus the distance between the destination and the subject's starting point. Starting points are common knowledge and are different for every subject in each period..$^{20}$ Groups are reshuffled in each period, and subjects do not know the identity of the other group members.

The only parameters that differed between subjects and rounds were the subjects' starting points, which determine their payoffs. Nevertheless, the exact same set of parameters was used across all 12 sessions. That is, for any combination of starting points used for a group in a specific round of a session, there was another group in all other sessions with the same starting points in the same round. Furthermore, the exact same sequence of parameters was assigned to subjects in all sessions. In total we used 100 distinct combinations of starting points: in each of the twenty rounds there was one for each of the five groups formed in each round.

Treatment - Median Approval ( $\boldsymbol{M A}$ ) In treatment $M A$, to choose the destination, each group member chooses an interval of integers between 1 and 100, and each location in the interval receives a

\footnotetext{
${ }^{20}$ We chose starting points in a way that maximized power for the experiment in terms of detecting a treatment effect in the second part. To that end, we ran simulations using many different sets of starting points and hypothesizing a treatment effect of magnitude and variance similar to what we found in the pilot session. We then chose the set of starting points where the effect was stronger in a linear regression similar to the one corresponding to the second column of Table 4. More details on the exact process are available upon request.
} 
single vote. The collective choice is the maximum median of the distribution of votes. Subjects choose the interval by moving specific bars on their screen that mark the lower and higher limits of the interval of votes.

Treatment - Simple Mean $(\boldsymbol{S M})$ In treatment $S M$ subjects can vote for a single location by choosing an integer between 1 and 100. The collective choice is the mean of all three votes. Voting takes place by moving a bar to the specific location that the subjects wishes to vote for.

Voting, information and time limit Voting in both treatments lasts for $60+x$ seconds, ${ }^{21}$ where $x$ is a number between 1 and 10, chosen randomly in each round and not known to the subjects. During this time, each subject is informed about her and others' starting points and can enter her votes (interval or single vote, depending on the treatment). She can also observe the votes entered by other group members in real time. At any given point in time the software calculates the destination and the group members' payoffs. These are shown on the screen as a clock counts down from one minute. At 10 seconds, a text starts blinking indicating that time is almost up, after which it turns red and indicates that voting may finish at any moment. The destination for the period is determined by the votes entered when the $60+x$ seconds finish. After that, a screen appears informing subjects about the results of the voting: each subject's votes, the final destination, and subjects' payoffs.

We use a voting process with real-time feedback to allow for fast within-round learning. ${ }^{22}$ A random ending point is used to discourage extreme "sniping" behavior, which was observed in a pilot session with fixed ending points. ${ }^{23}$

Random Dictator Game - Part B Part B is identical for both treatments. In each round of Part B, subjects are placed in the same groups as in the corresponding round of Part A. Again, the group needs to choose a collective destination from the same starting points as in the respective round of Part A. Unlike Part A, the choice is now made by a random dictator: Each group member proposes a location by choosing an integer between 1 and 100. One of the three proposals is chosen randomly as the group's

\footnotetext{
${ }^{21}$ For the first two periods this is extended to $90+x$ to allow subjects to get familiarized with the voting environment.

${ }^{22}$ Moreover, it has been shown that feedback exchange among players prior to the group decision point helps diminish outcome-related institutional differences (see, for instance, Goeree and Yariv, 2011; Gerardi and Yariv, 2007), which is desirable in our case.

${ }^{23}$ With a fixed end point, many subjects would significantly change their votes in the last seconds of voting in an effort to achieve a more favorable outcome. The term "sniping" has been used in online auctions to describe bidders that only submit a bid in the last moment to avoid driving up the price through a bidding war. See, for example, Ockenfels and Roth (2006).
} 
destination for the round, and payoffs are determined in the same manner as in Part A. Before making a proposal, subjects are reminded of all starting points, all votes, and the chosen destination in the corresponding round of Part A. They make a proposal by clicking on a location on the screen and then on a 'submit' button. They can revise their proposal as many times as they wish before clicking 'submit'. For each location they click, the software calculates and shows all players' payoffs if that proposal is selected. They cannot see the proposals of the other group members, and they are not informed about the others' proposals and the final outcome until the end of all rounds.

Matching protocol As mentioned, subjects are put in a new group in each of the 20 rounds in Part A and this matching is repeated in Part B. We reshuffle the groups to avoid repeated game effects. While subjects may meet another subject again, they cannot know when this happens. Furthermore, given that reshuffling happens among all session participants, the probability of playing with the same players in consecutive rounds is small. Despite this, one could still worry that behavior across groups within each session might not be independent. ${ }^{24}$ We deal with the issue in two ways: through design features that we expect to minimize such possibility, and through appropriate care in the econometric analysis of results. We explain the former here and defer discussion of the latter until presenting the results.

In random matching protocols the behavior of players in one group can affect their behavior in the other groups they participate in at later rounds. The effect is typically expected to be through the belief formation process: players update their beliefs about what others will do based on what they observed others doing in the past, and choose an optimal course of action based on these updated beliefs. For example, in a public good experiment, if one's peers did not contribute in one group, then the subject might expect his peers in the next group to do the same and therefore might decide to reduce his own contribution. The real time voting process used in Part A helps avoiding this problem. In this scenario a player can decide on her preferred choice by simply observing in real time what others are doing. There is less of a need to rely on her beliefs about what others might do.

In Part B, subjects do not receive any feedback after making their proposals until the end of the experiment. Thus, while of course others' voting behavior in Part A may affect one's proposals in Part B, there cannot be any direct dependency between different subjects' proposals.

\footnotetext{
${ }^{24}$ Logistic considerations did not allow the use of smaller within-session cohorts that could potentialy mitigate the problem. In fact, one may still argue that neither this, nor even using a one-shot design can fully avert session-effects (Fréchette, 2012).
} 
Payments After Part B is completed a message on the screen informs subjects about the outcomes of all rounds in both parts. One round from each part is chosen randomly, and payoffs in that round are used to determine the subjects' payment for the experiment. Subjects receive $€ 1$ for every 15 points earned in the selected round of each part, plus an additional $€ 3$ as a participation fee. Subjects earned $€ 13.27$ on average across all sessions.

\subsection{Hypotheses}

The experiment is designed in a way that allows us to test the hypotheses that can be derived from our theory. We state these hypotheses here as a guide to aid the reader through the result section.

In Part A groups make choices using a different mechanism in each treatment. As explained in section 3.1, the $M A$ and $S M$ mechanisms were chosen specifically to overcome the endogeneity of outcomes. Of course, the arguments given in support of choosing the particular mechanisms were purely theoretical and solely based on equilibrium predictions. It remains an empirical question whether subjects' behavior in the two mechanisms satisfies the desiderata stipulated in (8) and (9). We therefore formulate the following two hypotheses, which are auxiliary to our main research question, but nevertheless of interest in their own right.

Auxiliary Hypothesis A. The $M A$ and $S M$ mechanisms produce the same group outcomes:

$$
x(u, M A)=x(u, S M) .
$$

We should note here that for the purposes of econometric analysis to test our main hypotheses it will not be necessary for this auxiliary hypothesis to hold in an exact sense. This will be possible as long as the results from the two mechanisms are close in a statistical sense. We can then apply various robustness checks to check whether endogeneity remains an issue in our data.

Auxiliary Hypothesis B. Individuals' manifest support for the outcome is higher in the MA treatment compared to $S M$ (or $M A$ is more congruent than $S M$ ):

$$
c\left(x(u, M A), b_{M A}\right)>c\left(x(u, S M), b_{S M}\right) .
$$

Given the differences in the two mechanisms, there is no obvious choice of a measure for $c_{i}$ that does 
not suffer from a trade-off in informativeness when measuring manifest support for the outcome within versus across mechanisms. We discuss this further in sections 5.1.3. and 5.2.4.

Using the data from Part B we can test our main hypothesis, which compares levels of actual agreement following decisions made, and how these are expected to differ in each treatment:

Hypothesis 1. Post-outcome levels of actual agreement will be higher in the $M A$ treatment compared to $S M$ :

$$
S_{M A}^{1}<S_{S M}^{1}
$$

Assuming our main hypothesis holds true, we wish to understand the underlying rationale that drives it. Our reference-dependence theory posits the existence of an attractor effect that drives postoutcome ideal policies closer to the group outcome from Part A. Referring directly to equation (1), and interpreting proposals in Part B as subjects' post-outcome ideal points, we have the following hypothesis:

Hypothesis 2. Subjects' proposals in Part B are a convex combination of their starting points and the group outcome in Part A:

$$
\text { proposal }=\beta \cdot x+(1-\beta) \cdot h_{i}^{0}, \quad \beta \in[0,1]
$$

The "attractor effect" and its potential difference across treatments is captured by the following hypothesis to be tested:

Hypothesis 3. Subjects proposals in Part B are affected by the group outcome more in the $M A$ treatment than in $S M$ :

$$
\beta_{M A}>\beta_{S M}
$$

Concerning manifest support for the outcome as a driver in generating the "attractor effect" we need to consider separately one's own manifest support and that of others, as we do in (5) and (6). The relevant hypotheses are the following:

Hypothesis 4. Subjects proposals in Part B move closer to the group outcome when an individual's own manifest support for the outcome is high in both treatments.

$$
\frac{\partial \beta_{M A}}{\partial c_{i}}>0 \text { and } \frac{\partial \beta_{S M}}{\partial c_{i}}>0, \forall i
$$


Hypothesis 5. Subjects proposals in Part B move closer to the group outcome when others' manifest support for the outcome is high in both treatments.

$$
\frac{\partial \beta_{M A}}{\partial C_{i}}>0 \text { and } \frac{\partial \beta_{S M}}{\partial C_{i}}>0, \forall i
$$

\section{Results}

\subsection{Part A}

\subsubsection{Individual voting behavior}

Overall, we can say that the equilibrium predictions discussed in section 3.2 perform well in organizing the individual voting data in both treatments. In $M A$ there is on average a $72 \%$ overlap between subjects' vote intervals and those predicted by Nash equilibrium. ${ }^{25}$ In the $S M$ treatment, in $54.1 \%$ of cases subjects' votes coincide exactly with the corresponding equilibrium prediction. Being somewhat more permissive, this goes up to $70.3 \%$ when we look at cases where the vote is within five points from the Nash equilibrium prediction. We provide a more detailed analysis of individual behavior under the two voting mechanisms in the Appendix.

An important observation at this stage is that Nash equilibrium is a good predictor of voting behavior in our experiment, but at the same time one observes some deviations from equilibrium predictions. These will inevitably be reflected in the vote outcome. For the next step of our analysis we turn our attention to the outcomes of the voting process.

\subsubsection{Vote Outcomes}

Given individual voters' behavior compliance with equilibrium predictions, it is not surprising to see that the Nash equilibrium does a relatively good job of predicting the outcomes in both treatments. This is shown in Figure 3. The left panel shows the collective choices of all groups, in all rounds, for both treatments. Starting points in all groups are chosen so that the equilibrium outcome is constant and equal to $33\left(\approx \frac{100}{3}\right)$ when the median starting point in a group is below 33 . For values higher than

\footnotetext{
${ }^{25}$ This percentage is calculated based on the cases where there is a unique vote interval prediction for $M A$, which is true in $87.7 \%$ of total cases. More analysis comprising also the remaining cases can be found in the Appendix. The percentage of overlap is measured using the Bhattacharyya coefficient. This is calculated as follows: let $\lambda_{\text {int }} \in\{1,2, \ldots, 100\}$ be the length of the vote interval int $\in\{$ data,predicted,overlap $\}$. The coefficient is $B C=\frac{\lambda_{\text {overlap }}}{\sqrt{\lambda_{\text {data }} \cdot \lambda_{\text {predicted }}}}$. Notice that $0 \leq B C \leq 1$, with $B C=0$ when there is no overlap and $B C=1$ when the vote interval in the data exactly coicides with the one predicted by theory.
} 

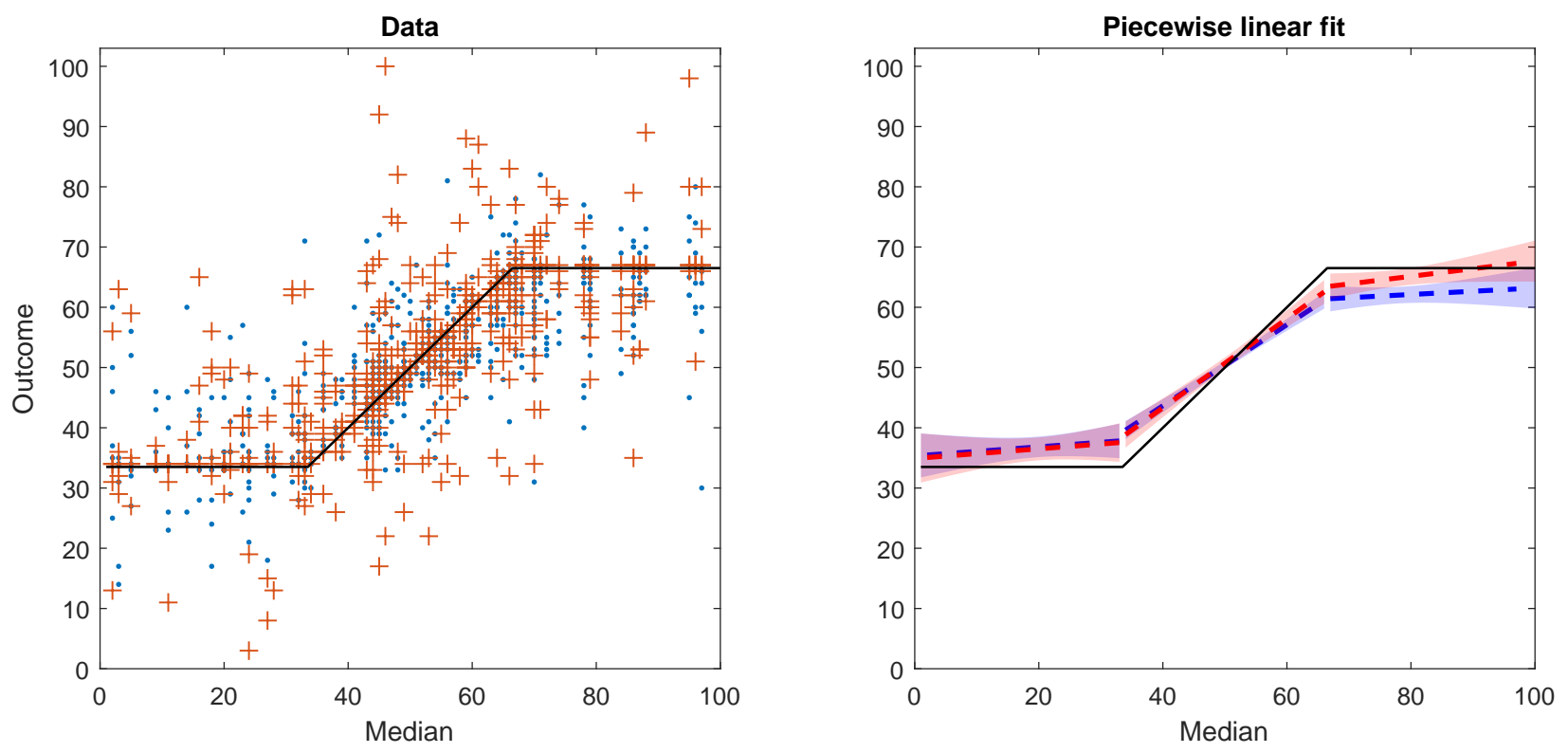

Figure 3: Collective choices for all groups in all rounds. Median refers to the group members' median starting point. The solid line in both panels corresponds to the Nash equilibrium outcome. For our choice of parameters this equilibrium depends entirely on the position of the median. In the left panel, data from the $M A$ and $S M$ treatments are indicated by dots and crosses respectively. In the right panel, dashed lines correspond to linear fits to the data with respect to the three Nash equilibrium regions, for the $M A$ and $S M$ treatments in blue and red, respectively. The corresponding shaded areas indicate $95 \%$ confidence intervals.

that, but lower than $67\left(\approx \frac{200}{3}\right)$, the equilibrium outcome coincides with the median starting point. The equilibrium is again constant and equal to 67 when the median exceeds that value. As we observe, the collective choice tends to be very close to the median when it lies between 33 and 67 . When the median is below or above this interval the dependency disappears, and the collective choice hovers around 33 and 67 .

The above is supported by the piecewise linear fits shown in the right panel of Figure 3. From this graph we also note that the outcomes in both treatments tend to be closer to the center of the range compared to the predicted Nash outcome. Overall, one can say that on average outcomes in the two treatments are close to each other. ${ }^{26}$ Still, it is clear from the left panel of Figure 3 that there are often substantial deviations of the outcome from equilibrium predictions. An important question then, given our Auxiliary Hypothesis 1, is whether these deviations give rise to systematic differences in the

\footnotetext{
${ }^{26}$ See also Figure 12 in the Appendix.
} 
TABle 2: Summary statistics of collective choices in Part A.

\begin{tabular}{|c|c|c|c|c|}
\hline Treatment & $\begin{array}{c}\text { average } \\
\text { absolute } \\
\text { deviation } \\
\text { from Nash }{ }^{\mathrm{a}}\end{array}$ & $\begin{array}{l}\text { average deviation } \\
\text { from } \\
\text { Nash to center }\end{array}$ & $\begin{array}{c}\text { average } \\
\text { efficiency } \\
(\% \text { of } \max )^{c}\end{array}$ & $\begin{array}{l}\text { average min to } \\
\text { max ratio }\end{array}$ \\
\hline $\begin{array}{c}\text { MA } \\
(N=600)\end{array}$ & $\begin{array}{c}5.56 \\
\text { (std 5.77) }\end{array}$ & $\begin{array}{c}3.10 \\
(\operatorname{std} 7.39)\end{array}$ & $\begin{array}{c}95.7 \\
\text { (std 4.72) }\end{array}$ & $\begin{array}{c}67.7 \% \\
\text { (std 13.7) }\end{array}$ \\
\hline $\begin{array}{c}\text { SM } \\
(N=600)\end{array}$ & $\begin{array}{c}5.46 \\
(\text { std } 7.57)\end{array}$ & $\begin{array}{c}2.13 \\
\text { (std } 9.09)\end{array}$ & $\begin{array}{c}95.6 \\
(\text { std } 5.37 \text { ) }\end{array}$ & $\begin{array}{c}65.2 \% \\
(\operatorname{std} 14.5)\end{array}$ \\
\hline $\begin{array}{l}\text { statistical } \\
\text { difference } \\
(p \text {-value })^{e}\end{array}$ & 0.936 & 0.150 & 0.873 & 0.004 \\
\hline
\end{tabular}

There are 600 observations in each treatment. Each observation $k$ refers to a group making a collective choice in a specific round. The standard deviation reported in parentheses is based upon these observations. Notice that observations cannot be assumed to be independent within sessions.

a The absolute deviation from Nash is calculated as: $\mid$ outcome $_{k}-$ Nash $_{k} \mid$.

b The deviation from Nash to center is calculated as: $\left(\right.$ outcome $_{k}-$ Nash $\left._{k}\right) \times \operatorname{sign}\left(50.5-\right.$ Nash $\left._{k}\right)$.

c Efficiency is calculated as: $\sum_{i}$ pay $_{i k}\left(\right.$ outcome $\left._{k}\right) / \sum_{i} \operatorname{pay}_{i k}\left(\operatorname{med}_{k}\right)$, where $\operatorname{pay}_{i k}(x)=100-$ $\mid$ start $_{i k}-x \mid$ and med $_{k}=$ median $\left(\right.$ start $\left._{i k}\right)$.

$\mathrm{d}$ The $\min$ to $\max$ ratio is calculated as: $\frac{\min \left\{p a y_{i k}\right\}}{\max \left\{\text { pay } y_{i k}\right\}}$.

e The p-values are obtained using a two sample Wilcoxon-Mann-Whitney test, taking session averages as the independent observations (six per treatment).

outcomes across treatments.

We further explore this issue by comparing the outcomes across treatments in three dimensions: their location, their efficiency, and their degree of inequality. Any of these dimensions could affect how an individual evaluates the collective choice. Table 2 summarizes the outcomes in each treatment across these dimensions.

Location As one can see from Figure 3, outcomes in the two treatments seem to lie close to each other in a statistical sense. This is further supported by comparing the distribution of absolute deviations from Nash and the distribution of deviations from Nash to the center (see Table 2, columns 2 and 3). In both cases the means are very close and their differences are not significantly different. ${ }^{27}$ Nevertheless, outcomes in $S M$ do seem to be more "noisy", as indicated by the higher standard deviation.

\footnotetext{
${ }^{27}$ Throughout the text we refer to differences as being statistically significant at the $5 \%$ level. We also report the p-value for the corresponding test.
} 
Efficiency In our setup, maximum efficiency is achieved when the collective choice coincides with the median starting point. Since collective choices are close to the Nash equilibrium outcome, which in turn coincides with the median for a broad range of observations, it is not surprising that high levels of efficiency are achieved in both treatments. Outcomes are slightly more efficient in the $M A$ treatment, but not significantly so.

Inequality We measure inequality in the payoffs associated with the outcome of a collective choice by taking the ratio of the lowest to highest payoff within each group. The lower the ratio, the highest the inequality in payments. In our setup, this measure is maximized when the collective choice coincides with the midpoint between the two more extreme group members. This point is also the maxmin choice: It maximizes the lowest payoff achieved by any group member. Outcomes in the $M A$ treatment are slightly less unequal than in $S M$. The difference is small in magnitude but statistically significant. It seems to be the consequence of outcomes being noisier in the $S M$ treatment. This finding is robust to measuring inequality in different ways, such as calculating the Gini index or simply looking at the minimum payoff.

Overall, even if outcomes in the two treatments are very similar in a statistical sense, they are not identical. In particular it appears that $S M$ produces on average outcomes with more unequal payoffs than $M A$. This is something we take into account in the analysis that follows. One thing to note is that despite the many cases of different outcomes produced by the two mechanisms, there is a remarkably high number of cases where the two mechanisms gave the same outcome for groups with the same starting points. ${ }^{28}$ So while Auxiliary Hypothesis $A$ does not hold unconditionally, our design will still allow us to identify treatment effects that go beyond any differences in outcome.

\subsubsection{Agreement and Mechanism Congruity}

Our premise for the choice of experimental design is that the $M A$ mechanism is more congruent than the $S M$ mechanism. We now quantify this claim and show how this difference is reflected in the data.

In section 3 we assumed that it is possible to measure the manifest support for an outcome of an individual, given her behavior in the collective choice mechanism (see equation (2)). We now need to

\footnotetext{
${ }^{28}$ If one picks randomly a group from a period in one of the experimental sessions of a treatment, there is a $53.5 \%$ chance that at least one group from the same period, with the same starting points, in one of the sessions of the other treatment, will have reached the same outcome \pm 1 points.
} 
choose a specific functional form for this measure. At this point we simply want to verify whether our Auxiliary Hypothesis B holds. Nevertheless, we also use this measure at a later stage to test some of our other hypotheses.

Given the differences of the two mechanisms, we need to select a measure of support that is applicable both to interval and single votes and that can provide a smooth estimate of outcome endorsement by each individual. We accomplish this by choosing a member of the family of measures described in equation (3). Let $x$ denote the group's outcome and $b_{i}$ be the set of all locations that subject $i$ votes for (in $S M$ this set is a singleton). Then our measure of manifest support $c\left(x, b_{i}\right)$ is given by taking the distance between $x$ and the subject's vote $v \in b_{i}$ that is closest to $x$. We subtract that from 100 and divide by 100. Formally,

$$
c\left(x, b_{i}\right)=\frac{100-\min \left\{|v-x|, \text { s.t. } v \in b_{i}\right\}}{100}
$$

The measure ranges from 0 (complete lack of support for the outcome) to 1 (the outcome is a location the individual voted for). The left panel of Figure 4 shows the empirical cdf for this measure for each treatment. $^{29}$ It is clear that treatment $M A$ displays substantially higher levels of manifest support for the outcome. In particular, about $80 \%$ of individual strategies in $M A$ exhibit the highest degree of outcome endorsement.

The middle and right panels of Figure 4 break-down the data for non-median and median voters. In both treatments we observe a more spread out distribution of manifest support among non-median voters. Nevertheless, it remains true that manifest support is on average significantly higher in $M A$ compared to $S M$.

In all cases, there is a stochastic dominance relationship in the manifest support levels between treatments, which indicates that subjects vote for alternatives closer to the outcome in $M A$ compared to $S M$, even if one focuses on cases where the outcome is not fully endorsed.

Based on all of the above observations we can conclude that there is substantial support for our Auxiliary Hypothesis B. There are higher levels of manifest support for the outcome in treatment $M A$ compared to $S M$. We conclude that Median Approval is a substantially more congruent mechanism than Simple Mean.

\footnotetext{
${ }^{29}$ Alternative measures can be constructed using, for instance, the average instead of minimum distance of votes from the outcome. Our results do not change qualitatively. Still, measuring support based on the minimum distance is a stronger predictor of proposals in Part B, both across and within treatments (see section 5.2.4).
} 

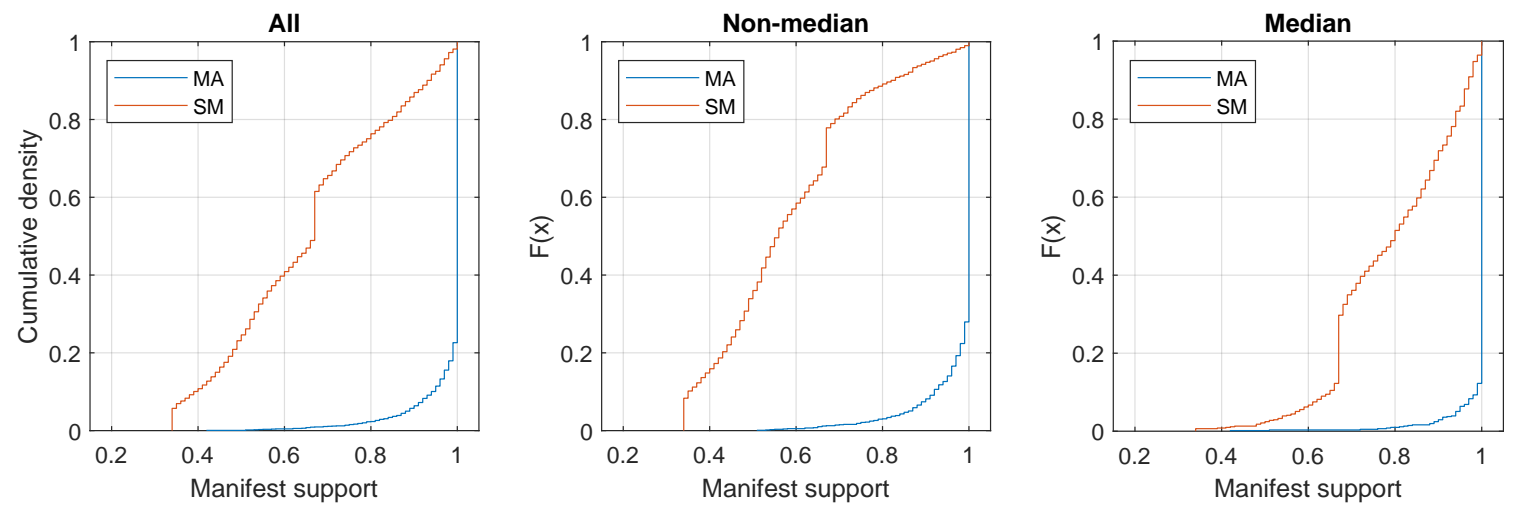

Figure 4: Measures of individuals' manifest support for the outcome. The left panel shows the empirical cdf for manifest support in each treatment. The middle and right panels show the empirical cdf's for manifest support in each treatment for different types of voters.

\subsection{Part B}

Recall from the previous section that in each round in Part B, subjects are put in the same group as in the corresponding round in Part A. They are shown the group's votes and outcomes in Part A and are assigned the same starting points. They are asked to propose a new destination for Part B. Proposals are not restricted in any way and can be any point between 1 and 100. For each group, one of the proposals is selected randomly to determine payoffs. Still, others' proposals, the randomly selected proposal, and the corresponding payoffs are not shown to subjects until the end of the experiment. Hence, for each individual, we have 20 proposals from different groups, which gives 1800 observations per treatment. We interpret individual proposals as a subject's post-outcome ideal policy.

\subsubsection{Actual Agreement}

We can now turn attention to our main hypothesis, Hypothesis 1, that groups in the $M A$ treatment achieve higher levels of post-outcome actual agreement than in the $S M$ treatment. The first column in Table 3 presents within-group dispersion of post-outcome ideal policies, measured by the standard deviation of group members' proposals. High levels of dispersion reflect high levels of actual disagreement 
TABle 3: Summary statistics of Disagreement in Part B.

\begin{tabular}{|c|c|c|c|}
\hline Treatment & $\begin{array}{c}\text { Standard } \\
\text { deviation } \\
\text { within group }\end{array}$ & $\begin{array}{c}\text { Conditional } \\
\text { on Part A } \\
\text { Nash } \pm 1\end{array}$ & $\begin{array}{c}\text { Across } \\
\text { treatment } \\
\text { same group } \\
\& \text { Part } A \pm 1\end{array}$ \\
\hline MA & $\begin{array}{c}18.95 \\
(\operatorname{std} 9.26, N=600)\end{array}$ & $\begin{array}{c}18.28 \\
(\operatorname{std} 9.21, N=158)\end{array}$ & - \\
\hline SM & $\begin{array}{c}23.90 \\
(\text { std } 10.12, N=600)\end{array}$ & $\begin{array}{c}25.15 \\
(\text { std } 10.61, N=280)\end{array}$ & - \\
\hline MA-SM & -4.95 & -6.87 & $\begin{array}{c}-5.62 \\
(\text { std } 10.27, N=139)\end{array}$ \\
\hline $\begin{array}{l}\text { treatment } \\
\text { effect } \\
(\mathrm{p} \text {-value })^{*}\end{array}$ & 0.004 & 0.007 & 0.016 \\
\hline
\end{tabular}

within a group. Disagreement is substantially lower in the $M A$ treatment and the difference is highly significant. ${ }^{30}$

Figure 5 gives a more detailed picture of the difference in disagreement in $M A$ compared to $S M$, after the Part A outcome. It breaks down observations based on the dispersion of individuals' starting points. These can be viewed as a proxy for disagreement before the Part A outcome. ${ }^{31}$ In both treatments there is a clear positive correlation between the dispersion of starting points and ex-post disagreement. It is also evident that ex-post disagreement in $M A$ is on average less than in $S M$ across the board. In particular, the dispersion of post-outcome ideal points is on average $76 \%$ of that of starting points. For $S M$ it is on average $96 \%$. This difference is statistically significant.

We summarize all the above in the following result:

Result 1:We find substantial support for Hypothesis 1. Post-outcome levels of actual agreement are

\footnotetext{
${ }^{30}$ This does not depend on how one measures dispersion. Similar results are obtained by using mean absolute deviation or the range instead of standard deviation.

${ }^{31}$ We do not elicit ideal policies before voting. These may not coincide with each subject's starting point, as social preferences such as inequity aversion or other factors could play a role. Nevertheless, given the incentives, it is reasonable to expect that groups with a higher dispersion of starting points also start off with higher levels of disagreement. In fact, as is discussed later on, in the majority of cases across treatments, subjects submit their starting point as their ideal-policy in Part B.
} 

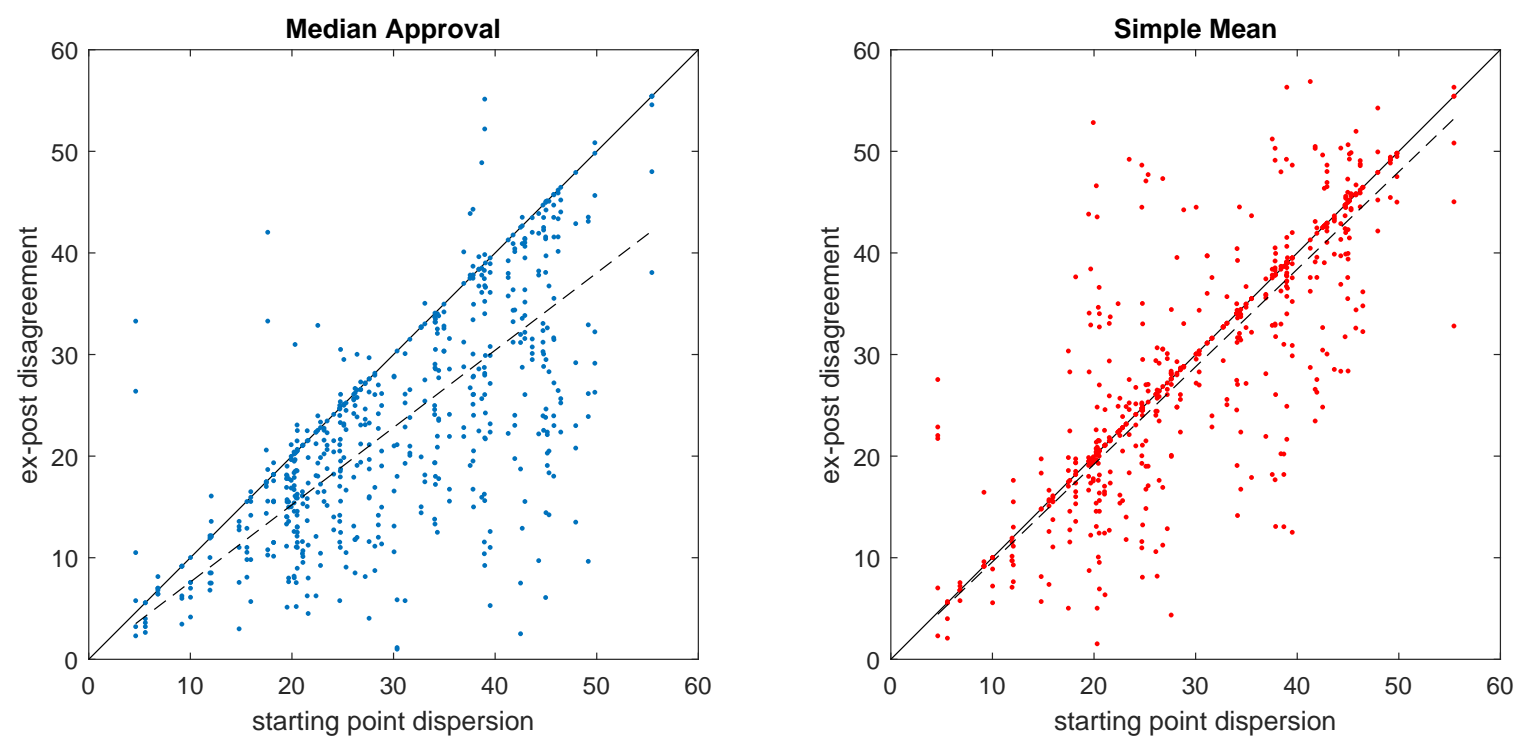

Figure 5: Disagreement conditional on starting points. Each point in the scatter plots corresponds to a group in one round. Values in the horizontal axis represent starting point dispersion, measured by the standard deviation of group members' starting points. Values in the vertical axis represent ex-post disagreement measured by the standard deviation of group members' proposals in Part B. The solid black lines are the 45 degree axis. Dashed lines indicate the best fit of a linear model with no constant to the corresponding data.

significantly higher in the MA treatment compared to SM.

At this point it is important to check the degree to which the above finding can be explained by differences in the Part A outcomes obtained in each treatment (see section 5.1.2). One way to do that is to limit attention to the cases where for the same set of starting points, groups in both treatments reached the same outcome in Part A.

Recall that we used the same starting point combinations in all sessions for all treatments. Therefore there are multiple ways in which the outcome of groups in one treatment can be matched to the outcome of similar groups in the other treatment. We show here the results of two such ways.

In the second column of Table 3 we compare disagreement in the same way as we do in the first column, but limit our sample in each treatment only to the cases where a group's outcome is at most one point away from the corresponding Nash prediction. This ensures that similar groups included from both treatments also have nearly identical outcomes. As shown in the table, the levels of disagreement in the two treatments are very close to the one of the full sample. 
As a further robustness check, in the last column of Table 3 we randomly match each session in treatment $M A$ to a session in treatment $S M$. Then, for each pair of sessions we find pairs of groups (one in each session with the same starting points) that also have nearly identical outcomes and calculate the difference in ex-post disagreement. As shown in the table, the average difference of disagreement for similar groups across treatments is statistically significant and at similar levels as the differences between treatment averages using either the full or the restricted sample.

Finally, as the only difference in outcomes between treatments that is statistically significant concerns the distribution of payoffs, we repeat the same exercise as in Figure 5, only this time, instead of splitting the data into the two treatments, we do so by the degree of inequality in outcomes. We find no differences in terms of the post-outcome disagreement (as a percentage of starting point dispersion) between the $50 \%$ of groups with the highest minimum to maximum payoff ratio and those with the lowest (see Figure 13 in the Appendix). The same is true if we split the sample by the deviation from Nash to center (see Figure 14 in the Appendix).

The take-away from these robustness checks is that the significantly larger agreement in $M A$ compared to $S M$ cannot be explained by any small differences in Part A outcomes that could not be explained by equilibrium theory. Having established the existence of a treatment effect in the direction we hypothesized, we turn our attention to individual behavior in order to understand the rationale behind this effect.

\subsubsection{The outcome as an attractor}

According to the framework we develop in section 3.1, the Part A outcome should act as an attractor and move voters' ideal points away from their starting point and closer to itself. In that case, and absent any other factors to influence preferences, subjects' proposals in Part B should be formed by putting some weight $\beta$ on the Part A outcome, and its complement $1-\beta$ on their starting point (see equation $(1))$.

In the first column of Table 4 we estimate this model and find that it does a good job fitting the data as it explains $83 \%$ of the variance in subjects' Part B proposals. According to this estimation, subjects' proposals put a weight $\beta$ of about $15 \%$ on the outcome from Part A. ${ }^{32,33}$

\footnotetext{
${ }^{32}$ The theoretical model does not have a constant term. We include one here as it serves as a simple robustness check. Essentially, including a constant term is a control for the possibility of subjects putting some weight on the center of the policy space: proposal $=\frac{\gamma}{\text { center }} \cdot$ center $+\beta \cdot x+\left(1-\beta-\frac{\gamma}{\text { center }}\right) \cdot h_{i}^{0}$. Results do not change if the constant is dropped.

${ }^{33}$ Results are also robust to the use of fixed-effect specifications.
} 
TABLE 4: OLS RESULTS

Dependent variable: proposals

\begin{tabular}{|c|c|c|c|c|c|c|}
\hline & \multicolumn{2}{|c|}{ Full Sample } & \multicolumn{2}{|c|}{ By treatment } & \multicolumn{2}{|c|}{ Only Nash \pm 1} \\
\hline & (1) & $(2)$ & $\begin{array}{l}\text { MA } \\
(3)\end{array}$ & $\begin{array}{l}\text { SM } \\
(4)\end{array}$ & $\begin{array}{l}\text { MA } \\
(5)\end{array}$ & $\begin{array}{l}\text { SM } \\
(6)\end{array}$ \\
\hline $\begin{array}{l}\text { Part A } \\
\text { outcome }(\hat{\beta})\end{array}$ & $\begin{array}{c}0.151^{* *} \\
{[0.062,0.242]}\end{array}$ & $\begin{array}{c}0.275^{* *} \\
{[.203, .346]}\end{array}$ & $\begin{array}{c}0.297^{* *} \\
{[0.168,0.361]}\end{array}$ & $\begin{array}{c}0.044 \\
{[-0.019,0.107]}\end{array}$ & $\begin{array}{c}0.320^{* *} \\
{[0.112,0.553]}\end{array}$ & $\begin{array}{c}-0.013 \\
{[-0.098,0.072]}\end{array}$ \\
\hline $\begin{array}{l}\text { Starting } \\
\text { point }\end{array}$ & $\begin{array}{c}0.827^{* *} \\
{[0.752,0.900]}\end{array}$ & $\begin{array}{c}0.722^{* *} \\
{[.661, .783]}\end{array}$ & $\begin{array}{c}0.723^{* *} \\
{[0.652,0.780]}\end{array}$ & $\begin{array}{c}0.926^{* *} \\
{[0.877,0.976]}\end{array}$ & $\begin{array}{c}0.712^{* *} \\
{[0.596,0.816]}\end{array}$ & $\begin{array}{c}0.956^{* *} \\
{[0.905,1.012]}\end{array}$ \\
\hline $\begin{array}{l}\text { Part A } \\
\text { outcome } \\
\times S M\end{array}$ & & $\begin{array}{c}-0.215^{* *} \\
{[-.292,-.138]}\end{array}$ & & & & \\
\hline $\begin{array}{l}\text { Starting point } \\
\times S M\end{array}$ & & $\begin{array}{c}0.206^{* *} \\
{[.137, .274]}\end{array}$ & & & & \\
\hline Constant & $\begin{array}{c}1.335 \\
{[-0.276,2.946]}\end{array}$ & $\begin{array}{c}0.633 \\
{[-.931,2.173]} \\
\end{array}$ & $\begin{array}{c}-0.603 \\
{[-3.299,2.134]} \\
\end{array}$ & $\begin{array}{c}1.604 \\
{[-0.443,3.740]}\end{array}$ & $\begin{array}{c}-0.486 \\
{[-9.249,8.107]}\end{array}$ & $\begin{array}{c}3.037 \\
{[-0.845,7.152]}\end{array}$ \\
\hline$R^{2}$ & .828 & .839 & .784 & .882 & .775 & .905 \\
\hline Observations & 3600 & 3600 & 1800 & 1800 & 474 & 840 \\
\hline
\end{tabular}

Notes: Confidence intervals (95\%) and p-values are obtained using wild cluster bootstrap, with robust errors clustered at the session and subject level (see Cameron et al., 2008; MacKinnon and Webb, 2018; Roodman et al., 2018).

$S M$ is a dummy variable and is equal to one for treatment $S M$.

${ }^{* *}: p-v a l<.01,{ }^{*}: p-v a l<.05$

Of course, based on this regression alone we cannot rule out that subjects are affected by other considerations and the positive coefficient of the Part A result is simply capturing those. For instance, if subjects care about equality of payoffs, then the point achieving the most equal payoffs may have a similar attractor effect. In the Appendix we consider this possibility, as well as the role of reciprocity. In particular, we introduce into our simple-framework the possibility for subjects to put some weight to the equality maximizing point, or to the starting-points of other subjects in the group. The data reveals no evidence of this being the case. We also construct a measure of perceived kindness to test whether reciprocity may influence the way subjects form their proposals, putting more weight on the starting point of group members that in Part A voted in way that can be perceived as kind to them. Our overall conclusion is that the finding about the weight $\beta$ put on the outcome of the Part A result is robust to such considerations (See Table 6 and the relevant discussion in the Appendix).

Overall, these findings support the use of our simple framework where the Part A result operates as 
an attractor. As we hypothesized, a subject's ideal point in Part B, as expressed in her proposal, moves away from the starting point and closer to the Part A result.

Result 2: We find strong support for Hypothesis 2. Proposals in Part B are well described by equation (1). Subjects assign a positive weight on the Part A result when submitting their preference in Part B.

In column 2 of Table 4 we add interactions between the explanatory variables and the treatment. This allows us to see how the weight $\beta$ (and its complement) changes across treatments. A different way to see this is to run the initial regression separately for both treatments, which we do in columns 3 and 4 . It is clear from these results that there is a significant treatment effect on the way subjects make proposals in Part $\mathrm{B}$ of the experiment. In $M A$ the estimated $\beta$ is just above a quarter. In contrast, in $S M$ the estimated $\beta$ is five times smaller, just above $5 \%$. This difference is also strongly statistically significant. These findings indicate that, while present in both treatments, the attractor effect is much stronger in $M A .^{34}$

The treatment effect we find is in line with our hypotheses. Still, we also hypothesize that such a treatment effect should be the result of the institutional features of the two mechanisms and the different behavioral response they induce on subjects, conditional on delivering the same outcome in Part A. As discussed previously, the outcomes in the two treatments are similar in a statistical sense, but far from identical (see section 5.1.2). It is therefore possible that the treatment effect on proposals that we find is because of these residual differences in outcomes across treatments. To rule this out we use a similar approach as in section 5.2.1. In columns 5 and 6 in Table 4 we run the same regressions for each treatment, limited only to the cases where the outcome in Part A was very close to the Nash prediction: either identical or deviating by just one point (which is the minimum possible deviation). The results are very similar to those obtained using all observations. If anything, the treatment effect seems to be even stronger in this case. In particular it appears that in $S M$ subjects use $\beta=0$ when the Part A outcome is very close to the Nash prediction. From this exercise, we conclude that the strong treatment effect we find on the magnitude of $\beta$ cannot be explained by any residual differences in the Part A outcomes in the two treatments.

As a final robustness check, we perform the regressions splitting the sample by the level of inequality in payoffs from the Part A outcome (see Table 7 in the Appendix). The estimated coefficients do not

\footnotetext{
${ }^{34}$ It is true that from column 4 we cannot reject that $\beta$ is zero in $S M$, at the $5 \%$ level. Still, from the regression in column 2 we can reject at the $5 \%$ significance level that the sum of the coefficients of the Part A outcome and that of its interaction with the treatment dummy are equal to zero.
} 
vary depending on the level of inequality in the sample used.

Result 3: We find strong support for Hypothesis 3. In treatment MA subjects assign a higher weight on the Part A outcome, compared to SM, when submitting their preference in Part B. This effect does not seem to be explained by differences in outcomes across the two treatments.

\subsubsection{Heterogeneity in $\beta$}

We hypothesize in section 4.2 that an important factor driving the differences in the attractor effect $\beta$ across treatments is the degree of manifest support for the outcome induced by each mechanism. Before trying to establish whether there is a relation between manifest support and $\beta$ it is useful to take a closer look at the heterogeneity in $\beta$ 's across decisions in both treatments.

Solving equation (1) for $\beta$ gives:

$$
\beta=\frac{h_{i}^{1}-h_{i}^{0}}{x-h_{i}^{0}} .
$$

By using the starting points for $h_{i}^{0}$, subjects' Part B proposals for $h_{i}^{1}$, and the Part A outcome for $x$ we can infer the weight $\tilde{\beta}_{i r}$ used by each subject $i$ in each round $r$. Two things to note are the following:

first, $\tilde{\beta}_{i r}$ is not defined for the cases where $x_{r}$, the group's outcome in Part A in round $r$, is equal to $h_{i r}^{0}$, $i$ 's starting point in the same round; second, while in theory $\beta \in[0,1]$, it is possible to have $\tilde{\beta}_{\text {ir }}$ being negative or greater than one, as there are no relevant restrictions imposed on subjects when making proposals in Part B.

Figure 6 shows the distribution of $\tilde{\beta}_{i r}$ in the data for each treatment, and broken down by type of voter. There are 184 cases (out of a total of 3600) where $\tilde{\beta}_{i r}$ is not defined: 63 in $M A$ and 121 in $S M$. We also observe that in $84 \%$ of cases $\tilde{\beta}_{i r} \in[0,1](85.4 \%$ in $M A$ and $82.7 \%$ in $S M)$.

A feature that stands out in all graphs of Figure 6 is that in a significant proportion of cases we have $\tilde{\beta}_{i r}=0$. This is indicated by the jump of the empirical cdf at zero. A $\tilde{\beta}_{i r}$ of zero indicates that in that particular round a subject made a proposal equal to her starting point. This happens in $44.8 \%$ of cases in $M A$ and $63.4 \%$ in $S M$. Note that this difference in frequency is in line with our finding from the previous section regarding the treatment effect on $\beta$. It is important to point out that what we observe here is not driven by some subset of individuals persistently proposing their starting point while others make proposals that are different than their starting point. While there is some heterogeneity across individuals, there is also significant heterogeneity within individuals' proposals. Only 1 out of 180 subjects proposed his/her starting point in all 20 rounds of Part B, while all subjects proposed their 

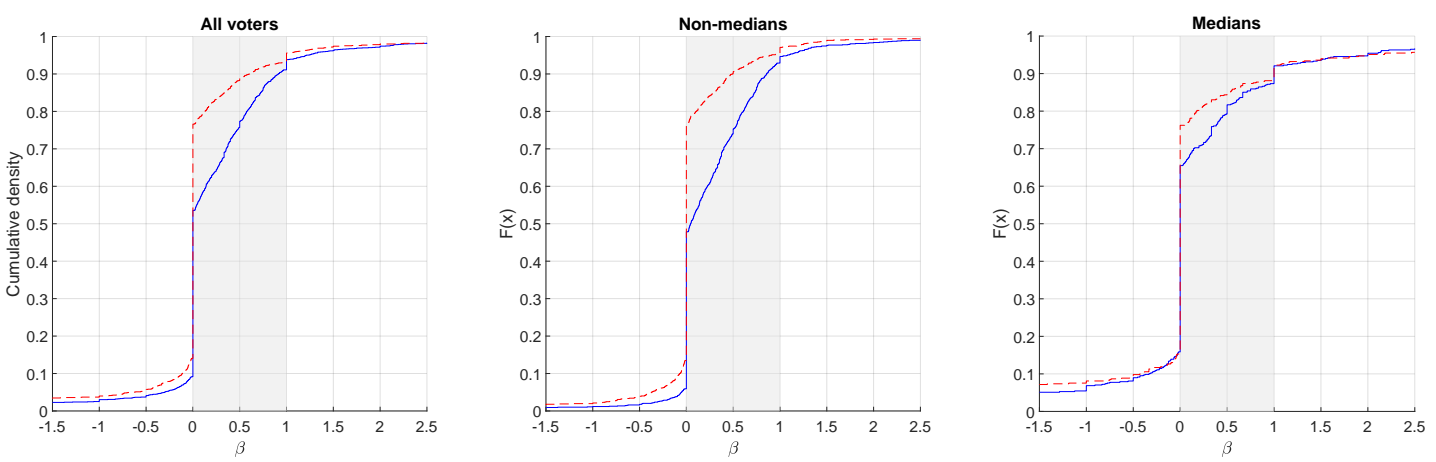

Figure 6: Empirical distribution of $\beta$. The graphs show the empirical cdf's for $\beta$ in each treatment. Blue solid lines are for the $M A$ treatment and red dashed lines for the $S M$ treatment. The left panels shows the distribution for all voters, while for the other two panels we split the voters into non-medians (center) and medians (right). Theoretical values of $\beta$ should lie in the $[0,1]$ interval (shaded). The graphs are truncated at -1.5 below and 2.5 above for presentation purposes.

own starting point at least once. The graphs in Figure 6 also reveal that the difference across treatments is more evident in the behavior of subjects when they are in the role of a non-median voter.

\subsubsection{The role of manifest support for the outcome}

Our final hypotheses regard the positive relationship between manifest support for an outcome and the attractor effect $\beta$. As we discuss, manifest support for an outcome has two dimensions: the support exhibited by oneself and that exhibited by other group members. We hypothesize that both dimensions, for different reasons, are related to $\beta$ in the same way. Here we present evidence that supports only part of this theory. In particular we find that one's own level of manifest support positively affects $\beta$, but there is no evidence linking $\beta$ to others' manifest support for the Part A outcome.

The way we do this is by estimating different models that explain $\tilde{\beta}_{i r}$ and establishing whether a measure of manifest support for the outcome in Part A explains some of the variation we observe. Given the distribution of $\tilde{\beta}_{i r}$ and, in particular, the concentration of a mass of observations on zero, it is appropriate to use a two-part mixture model: the first part models a binary choice of either setting $\tilde{\beta}_{i r}=0$, i.e. propose one's starting point, or not; the second models the choice of $\tilde{\beta}_{i r}$ conditional on being non-zero. i.e. the outcome of the first part. We use a probit model for the first part and OLS for the second. As is standard when using two-part models, we always use the same set of regressors for both parts. 
TABLE 5: TWO-PART MODEL

Dependent variable: $\tilde{\beta}_{i r}$, the weight on the Part A result

\begin{tabular}{|c|c|c|c|c|c|}
\hline & (1) & $\begin{array}{l}\text { Full Sample } \\
\qquad(2)\end{array}$ & (3) & $\begin{array}{l}\text { MA } \\
(4)\end{array}$ & $\begin{array}{l}\text { SM } \\
(5)\end{array}$ \\
\hline \multicolumn{6}{|c|}{ First-part: probit } \\
\hline Constant & $\begin{array}{c}-0.099 \\
(.328)\end{array}$ & $\begin{array}{l}0.054 \\
(.618)\end{array}$ & $\begin{array}{c}-1.001^{*} \\
(.033)\end{array}$ & $\begin{array}{c}-0.044 \\
(.890)\end{array}$ & $\begin{array}{c}-1.185^{* *} \\
(.004)\end{array}$ \\
\hline $\begin{array}{l}\text { Treatment } \\
(\mathrm{SM}=1)\end{array}$ & & $\begin{array}{c}-0.477^{* *} \\
(.004)\end{array}$ & $\begin{array}{c}-0.131 \\
(.517)\end{array}$ & & \\
\hline $\begin{array}{l}\text { Voter type } \\
(\text { Non-median=1) }\end{array}$ & & $\begin{array}{l}0.114 \\
(.127)\end{array}$ & $\begin{array}{l}0.175^{*} \\
(.015)\end{array}$ & $\begin{array}{l}0.212^{*} \\
(.030)\end{array}$ & $\begin{array}{l}0.119 \\
(.285)\end{array}$ \\
\hline $\begin{array}{l}\text { Own } \\
\text { support }\end{array}$ & & & $\begin{array}{l}0.745^{*} \\
(.023)\end{array}$ & $\begin{array}{l}0.068 \\
(.919)\end{array}$ & $\begin{array}{l}0.766^{*} \\
(.033)\end{array}$ \\
\hline $\begin{array}{l}\text { Others' } \\
\text { support }\end{array}$ & & & $\begin{array}{l}0.433 \\
(.419)\end{array}$ & $\begin{array}{l}-0.052 \\
(.264)\end{array}$ & $\begin{array}{l}0.610 \\
(.301)\end{array}$ \\
\hline \multicolumn{6}{|c|}{ Second-part: OLS } \\
\hline Constant & $\begin{array}{c}0.327^{* *} \\
(.002)\end{array}$ & $\begin{array}{l}0.300 \\
(.088)\end{array}$ & $\begin{array}{l}1.466 \\
(.401)\end{array}$ & $\begin{array}{c}-4.247 \\
(.062)\end{array}$ & $\begin{array}{l}1.574 \\
(.180)\end{array}$ \\
\hline $\begin{array}{l}\text { Treatment } \\
(\mathrm{SM}=1)\end{array}$ & & $\begin{array}{c}-0.284 \\
(.080)\end{array}$ & $\begin{array}{c}-0.694 \\
(.291)\end{array}$ & & \\
\hline $\begin{array}{l}\text { Voter type } \\
(\text { Non-median=1) }\end{array}$ & & $\begin{array}{l}0.195 \\
(.375)\end{array}$ & $\begin{array}{l}0.346 \\
(.061)\end{array}$ & $\begin{array}{l}0.399^{*} \\
(.018)\end{array}$ & $\begin{array}{l}0.217 \\
(.663)\end{array}$ \\
\hline $\begin{array}{l}\text { Own } \\
\text { support }\end{array}$ & & & $\begin{array}{l}0.777 \\
(.398)\end{array}$ & $\begin{array}{c}1.287^{* *} \\
(.008)\end{array}$ & $\begin{array}{l}0.475 \\
(.632)\end{array}$ \\
\hline $\begin{array}{l}\text { Others' } \\
\text { support }\end{array}$ & & & $\begin{array}{l}-3.111 \\
(.181)\end{array}$ & $\begin{array}{l}4.797 \\
(.258)\end{array}$ & $\begin{array}{l}-4.274 \\
(.146)\end{array}$ \\
\hline Log-likelihood & -6235.82 & -6170.13 & -6157.14 & -3330.21 & -2742.85 \\
\hline Observations & 3416 & 3416 & 3416 & 1737 & 1679 \\
\hline
\end{tabular}

Notes: The numbers in parenthesis are the p-values that are obtained using wild cluster bootstrap, with robust errors clustered at the session and subject level.

$* *: p-v a l<.01$

$*: p-v a l<.05$

We start with the simplest such model to set the foundations for the subsequent analysis. The first column of Table 5 estimates a two-part model using only a constant in both parts. The estimated 
coefficient for the constant in the first part is not statistically different than zero. This indicates that without considering any other variables, it appears as if subjects' decision to set $\tilde{\beta}_{i r}=0$ or not is decided by the flip of a fair coin. The estimated coefficient for the constant in the second part indicates that conditional on not setting $\tilde{\beta}_{i r}$ equal to zero, the expected value of $\tilde{\beta}_{i r}$ is $0.327 .^{35}$

In the second column of Table 5 we add dummy variables for the treatment and type of voter. The signs of the estimated coefficients all match what is visible in Figure 10. From the first part we find that subjects in $S M$ are more likely to propose their starting point as the outcome for Part B. The same is true for subjects when they are medians, although the coefficient here is not statistically significant. From the second part we find that conditional on not proposing their starting point, subjects in $S M$, on average, make proposals with less weight on the Part A outcome. Notice, though, that the coefficient is not significant at the $5 \%$ level. We also find subjects putting a higher weight on the Part A outcome when they are non-medians, but again this is not statistically significant.

We now introduce into the model our measure of manifest support for the Part A outcome (see section 5.1.3). It enters the model in two variables: own support is the measure of manifest support exhibited by an individual for the group outcome, given by $c_{i}\left(x, b_{i}\right)$; others' support measures the average manifest support by other group members and is given by $C_{i}\left(x, b_{-i}\right)=\frac{1}{2} \sum_{j \neq i} c_{j}\left(x, b_{j}\right)$. Our hypotheses claim that both these measures positively affect the weight $\beta$ put on the Part A outcome.

Column 3 of Table 5 shows the estimated coefficients from a model including these two measures. All coefficients have the expected sign, except for others' support in the second part. Importantly, the introduction of the measures of manifest support removes the significance of the treatment effect in the first part. In particular it is one's own support for the Part A outcome that has a significant effect on whether or not to propose one's own starting point in Part B. An increase of own support by one standard deviation (with other variables at their average value) increases the probability of using $\tilde{\beta}_{i r} \neq 0$ by $6.14 \%$. This is roughly the same as the effect of being a non-median voter, which is the other variable with a statistically significant coefficient in the first part of this model. The effect of others' support is not statistically significant. In the second part, it cannot be rejected that the coefficients for both measures of manifest support are equal to zero.

Regarding the role of others' support, our results are not encouraging. At the same time, they suggest that own support may be driving to some extent subjects behavior when making proposals in Part B of our experiment. Still, we know from section 5.1.3 that this measure differs significantly between

\footnotetext{
${ }^{35}$ We estimate the $95 \%$ confidence interval to be $[.157, .497]$, comfortably within the theoretical $[0,1]$ interval.
} 
treatments, as this was one of our desired design features in choosing the two mechanisms. What the regression in column 3 of Table 5 shows about own support may simply be due to these differences picking up the effect of some other feature that differs between the two mechanisms and results in the observed differences in behavior in Part B of both treatments. Therefore, to establish whether own support plays a role by itself we look at behavior separately in each treatment. If our hypothesis is correct, that higher levels of manifest support for an outcome move preferences closer to that outcome, then this should also happen within the context of the same treatment. Any support for such an effect found here cannot be attributed to "unaccounted for" differences in the two mechanisms. ${ }^{36}$

In columns 4 and 5 of Table 5 we estimate the model separately for the data from each treatment. For $S M$ (in columns 5) the results are very similar to those obtained when using the full sample. For $M A$ there are some differences, notably that own support's effect disappears in the first part, but becomes significant in the second part. Prima facie it appears that manifest support for the outcome matters in different ways in each treatment. Nevertheless, one must keep in mind that the way we measure manifest support is the result of a compromise: we required a measure that could be equally applied to both mechanisms to allow for an easy comparison. As can be seen in Figure 4 the measure we use is distributed very differently within each treatment, being extremely skewed in $M A$. In the Appendix (Table 8) we provide the results of similar regressions where instead of the continuous measure of manifest support used here, we use a dummy variable that captures whether the Part A outcome is included in a subject's vote set $b_{i}$. The within-treatment regression for $M A$ reveals that manifest support (if measured this way) plays a similar role also for the first part of the model as we show here that it does for $S M$.

We summarize the discussion above in the following two results:

Result 4: We find significant support for Hypothesis 4. A subject's weight on the Part A outcome is increasing in the degree of its own manifest support for that outcome. This is true even within each treatment, and therefore the finding cannot be attributed to other latent differences across treatments.

Result 5: We do not find support for Hypothesis 5. Other's manifest support does not seem to influence the weight put on the Part A outcome when forming preferences in Part B.

\footnotetext{
${ }^{36}$ This is not to say that we can rule out other factors shaping behavior in parallel with manifest support. See the next section for further discussion.
} 


\section{Concluding remarks}

Our experimental results support our main premise that the way collective choice procedures are designed may affect participants' preferences. In particular, we hypothesize and confirm that groups making decisions using a more congruent mechanism exhibit higher levels of post-decision agreement among group members. We propose two behavioral channels through which a mechanism's congruity can affect preferences and actual agreement. We find evidence that supports the idea that individuals' desire to maintain consistency among their choices and their preferences may be driving the treatment effect we find. On the other hand, we do not find any evidence to support the notion that the effect is driven by the desire of individuals to align their preferences with those of others. In fact, more generally, we do not find evidence to suggest that the change in behavior across treatments that we observe in our experiment is induced by other-regarding preferences or reciprocity. And while we cannot exclude the possibility for such factors to affect behavior here, our results seem to be robust to such considerations.

We must stress that our analysis regarding what compels individuals to change their preferences after the group's decision is taken is not conclusive. First of all, our design's main aim was to distinguish the effect of different voting rules on a group's level of actual agreement. And while, as discussed, we do find evidence to support some of our conjectures, it does not allow us to causally link a particular behavioral channel with the observed treatment effect. Second, there might exist variables affecting preferences that we have not accounted for, and which depend on the exact voting mechanism. Unless these variables vary within a particular voting mechanisms in a manner that is correlated with individuals' own manifest support for the outcome, the case in support of the latter still stands. We could not come up with any such additional factors, but this does not preclude their existence.

Finally, subjects in the lab make decisions in a highly abstract and stylized environment, interacting only through computers and with rather salient monetary incentives. It is possible that under these conditions in our experiment, common drivers of behavior such as reciprocity or other-regarding preferences were muted. We cannot exclude that under different circumstances such considerations may play a significant role on individuals' behavior during and after collective decision-making. Nevertheless, even if that is the case, having these other-regarding factors being mute in our experiment allowed us to uncover the possibility of procedures affecting preferences through a self-regarding channel, namely individuals' desire for self-consistency. 


\section{References}

Aaron, H. J. (1994): "Distinguished lecture on economics in government: public policy, values, and consciousness," Journal of Economic Perspectives, 8, 3-21.

Acharya, A., M. Blackwell, AND M. Sen (2018): "Explaining preferences from behavior: a cognitive dissonance approach," The Journal of Politics, 80, 400-411.

BandurA, A. ET AL. (1991): "Social cognitive theory of self-regulation," Organizational Behavior and Human Decision Processes, 50, 248-287.

Beasley, R. K. And M. R. Joslyn (2001): "Cognitive dissonance and post-decision attitude change in six presidential elections," Political Psychology, 22, 521-540.

Becker, G. S. (1993): "Nobel lecture: The economic way of looking at behavior," Journal of Political Economy, 101, 385-409.

Bolton, G. E. And A. OCKenfels (2000): "ERC: A theory of equity, reciprocity, and competition," American Economic Review, 90, 166-193.

Bowles, S. (1998): "Endogenous preferences: the cultural consequences of markets and other economic institutions," Journal of Economic Literature, 36, 75-111.

Cameron, A. C., J. B. Gelbach, and D. L. Miller (2008): "Bootstrap-based improvements for inference with clustered errors," The Review of Economics and Statistics, 90, 414-427.

Charness, G. And M. Rabin (2002): "Understanding social preferences with simple tests," The Quarterly Journal of Economics, 117, 817-869.

Corazzini, L., S. Kube, M.-A. Maréchal, And A. Nicolo (2014): "Elections and deceptions: an experimental study on the behavioral effects of democracy," American Journal of Political Science, $58,579-592$.

Dal Bó, P., A. Foster, And L. Putterman (2010): "Institutions and behavior: Experimental evidence on the effects of democracy," American Economic Review, 100, 2205-29.

De Dreu, C. K. And L. R. Weingart (2003): “Task versus relationship conflict, team performance, and team member satisfaction: a meta-analysis." Journal of Applied Psychology, 88, 741. 
De Wit, F. R., L. L. Greer, And K. A. JeHn (2012): "The paradox of intragroup conflict: a meta-analysis." Journal of Applied Psychology, 97, 360.

Dufwenberg, M. And G. Kirchsteiger (2004): "A theory of sequential reciprocity," Games and Economic Behavior, 47, 268-298.

FAlK, A. AND U. FischBacher (2006): "A theory of reciprocity," Games and Economic Behavior, 54, 293-315.

Fehr, E. And K. M. Schmidt (1999): “A theory of fairness, competition, and cooperation," Quarterly Journal of Economics, 114, 817-868.

Festinger, L. (1962): A theory of cognitive dissonance, vol. 2, Stanford university press. (1964): "Conflict, decision, and dissonance." .

Fischbacher, U. (2007): “z-Tree: Zurich toolbox for ready-made economic experiments," Experimental economics, 10, 171-178.

Fischbacher, U. And F. Föllmi-Heusi (2013): "Lies in disguise? An experimental study on cheating," Journal of the European Economic Association, 11, 525-547.

FrÉchette, G. R. (2012): "Session-effects in the laboratory," Experimental Economics, 15, 485-498.

Frey, B. S., M. Benz, And A. Stutzer (2004): "Introducing procedural utility: Not only what, but also how matters," Journal of Institutional and Theoretical Economics JITE, 160, 377-401.

Frey, B. S. And A. Stutzer (2005): "Beyond outcomes: measuring procedural utility," Oxford Economic Papers, 57, 90-111.

Gerardi, D. AND L. YARIV (2007): "Deliberative voting," Journal of Economic Theory, 134, 317-338.

Gershkov, A., B. Moldovanu, And X. Shi (2017): "Optimal voting rules," The Review of Economic Studies, 84, 688-717.

GneEzy, U. (2005): "Deception: The role of consequences," American Economic Review, 95, 384-394.

Goeree, J. K. And L. YARIV (2011): “An experimental study of collective deliberation,” Econometrica, 79, 893-921. 
GREINER, B. (2015): "Subject pool recruitment procedures: organizing experiments with ORSEE," Journal of the Economic Science Association, 1, 114-125.

Grossman, G. And D. Baldassarri (2012): "The Impact of Elections on Cooperation: Evidence from a Lab-in-the-Field Experiment in Uganda," American Journal of Political Science, 56, 964-985.

Hartnett, T. (2011): Consensus-Oriented Decision-Making: the CODM model for facilitating groups to widespread agreement, New Society Publishers.

Insko, C. A. AND J. Schopler (1967): "Triadic consistency: A statement of affective-cognitiveconative consistency." Psychological Review, 74, 361.

JEHN, K. A. (1994): "Enhancing effectiveness: An investigation of advantages and disadvantages of value-based intragroup conflict," International Journal of Conflict Management, 5, 223-238.

Jehn, K. A., C. Chadwick, And S. M. Thatcher (1997): "To agree or not to agree: The effects of value congruence, individual demographic dissimilarity, and conflict on workgroup outcomes," International Journal of Conflict Management, 8, 287-305.

Jehn, K. A. And E. A. Mannix (2001): "The dynamic nature of conflict: A longitudinal study of intragroup conflict and group performance," Academy of Management Journal, 44, 238-251.

KAmEI, K. (2016): "Democracy and resilient pro-social behavioral change: an experimental study," Social Choice and Welfare, 47, 359-378.

Kamei, K., L. Putterman, And J.-R. Tyran (2015): "State or nature? Endogenous formal versus informal sanctions in the voluntary provision of public goods," Experimental Economics, 18, 38-65.

KamenicA, E. (2012): "Behavioral Economics and Psychology of Incentives," Annual Review of Economics, 4, 427-452.

Kellermanns, F. W., J. Walter, C. Lechner, and S. W. Floyd (2005): "The lack of consensus about strategic consensus: Advancing theory and research," Journal of Management, 31, 719-737.

Kelman, H. C. (1958): "Compliance, identification, and internalization three processes of attitude change," Journal of Conflict Resolution, 2, 51-60. 
Levine, D. K. (1998): "Modeling altruism and spitefulness in experiments," Review of Economic Dynamics, 1, 593-622.

Lind, E. A. And T. R. TyleR (1988): The social psychology of procedural justice, Springer Science \& Business Media.

MacKinnon, J. G. And M. D. WeBb (2018): "The wild bootstrap for few (treated) clusters," The Econometrics Journal, 21, 114-135.

Markussen, T., L. Putterman, and J.-R. Tyran (2013): "Self-organization for collective action: An experimental study of voting on sanction regimes," Review of Economic Studies, 81, 301-324.

Markussen, T., E. Reuben, and J.-R. Tyran (2014): "Competition, Cooperation and Collective Choice," The Economic Journal, 124, F163-F195.

Mason, R. O. And I. I. MitrofF (1981): Challenging strategic planning assumptions: Theory, cases, and techniques, John Wiley \& Sons Inc.

Mazar, N., O. Amir, And D. Ariely (2008): "The dishonesty of honest people: A theory of selfconcept maintenance," Journal of Marketing Research, 45, 633-644.

Mellizo, P., J. Carpenter, And P. H. Matthews (2014): "Workplace democracy in the lab," Industrial Relations Journal, 45, 313-328.

Moulin, H. (1980): "On Strategy-proofness and Single Peakedness," Public Choice, 35, 437-455.

Mullainathan, S. And E. Washington (2009): "Sticking with your vote: Cognitive dissonance and political attitudes," American Economic Journal: Applied Economics, 1, 86-111.

NúÑez, M. AND D. Xefteris (2017): "Implementation via approval mechanisms," Journal of Economic Theory, 170, 169-181.

OCKenfels, A. And A. E. Roth (2006): "Late and multiple bidding in second price Internet auctions: Theory and evidence concerning different rules for ending an auction," Games and Economic behavior, $55,297-320$.

Potters, J. And S. Suetens (2009): "Cooperation in experimental games of strategic complements and substitutes," The Review of Economic Studies, 76, 1125-1147. 
Priem, R. L., D. A. Harrison, And N. K. Muir (1995): "Structured conflict and consensus outcomes in group decision making," Journal of Management, 21, 691-710.

RABIN, M. (1993): "Incorporating fairness into game theory and economics," American Economic Review, 1281-1302.

Renault, R. And A. Trannoy (2005): "Protecting minorities through the average voting rule," Journal of Public Economic Theory, 7, 169-199.

Roodman, D. M., J. G. MacKinnon, M. Ø. Nielsen, And M. Webb (2018): "Fast and wild: Bootstrap inference in Stata using boottest," Tech. rep., Queen's Economics Department Working Paper.

Schweiger, D. M., W. R. SAndberg, And J. W. RAgan (1986): "Group approaches for improving strategic decision making: A comparative analysis of dialectical inquiry, devil's advocacy, and consensus," Academy of management Journal, 29, 51-71.

Schweiger, D. M., W. R. Sandberg, and P. L. Rechner (1989): "Experiential effects of dialectical inquiry, devil's advocacy and consensus approaches to strategic decision making," Academy of Management Journal, 32, 745-772.

SEn, A. (1997): "Maximization and the Act of Choice," Econometrica, 745-779.

Sutter, M., S. Haigner, And M. G. Kocher (2010): "Choosing the carrot or the stick? Endogenous institutional choice in social dilemma situations," The Review of Economic Studies, 77, $1540-1566$.

Thibaut, J. W. And L. Walker (1975): Procedural justice: A psychological analysis, L. Erlbaum Associates.

Tyran, J.-R. AND L. P. FELD (2006): "Achieving compliance when legal sanctions are non-deterrent," The Scandinavian Journal of Economics, 108, 135-156.

Walker, J. M., R. Gardner, A. Herr, and E. Ostrom (2000): "Collective choice in the commons: experimental results on proposed allocation rules and votes," The Economic Journal, 110, $212-234$.

Yamamura, H. And R. Kawasaki (2013): "Generalized Average Rules as stable Nash mechanisms to implement generalized median rules," Social Choice and Welfare, 40, 815-832. 


\section{A Additional analysis}

\section{A.1 Voting process}

One difference between the voting mechanisms that is worth noting concerns the degree to which a single voter can affect the outcome, given the others' votes. In $M A$ the outcome can, theoretically, move up to 98 points by a single individual's change in votes, but only for very particular choices of the rest of the players. This happens in the extreme scenario where all voters cast a single vote on location 1 . Then one of them can switch and vote the interval [99,100], moving the outcome from 1 to 99. In most scenarios, a single voter's power over the outcome is quite limited: When two voters approve many alternatives, the median of the induced vote distribution is moderately responsive to a change in the strategy of the third voter. On the other hand, in $S M$, it is always possible for a single voter to move the outcome to any point within a range of 33 points. Moreover, in $S M$, it is also practically easier to move the outcome since an individual's vote can change to any other with a single move of the computer mouse, while in $M A$ a change to a different strategy involves a two-step process: A subject needs to change one end of the interval before making a change to the other.
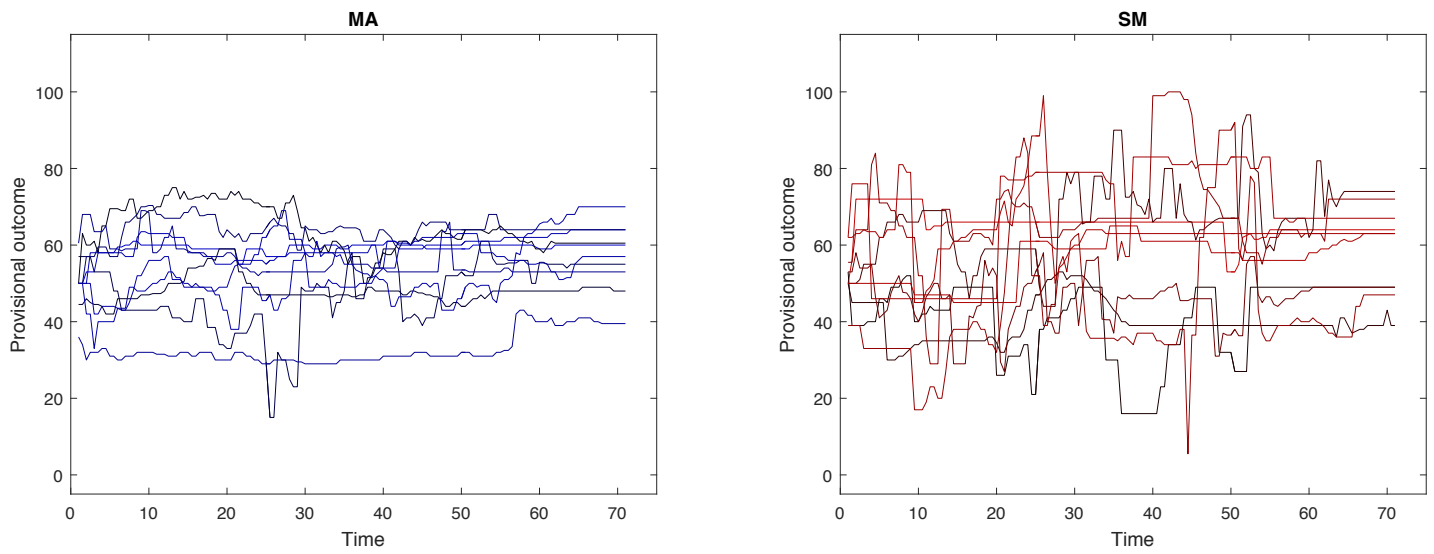

Figure 7: Volatility of collective choices. The left panel shows 10 randomly chosen groups and how the provisional outcome changes across time during the voting process in the $M A$ treatment. The right panel shows the same for 10 groups with the same starting points in the $S M$ treatment.

In the two panels of Figure 7, we show the provisional outcomes across time for 10 randomly chosen groups in each treatment. A common pattern emerges for all groups. In $M A$, movements are more gradual. Substantial movements happen mostly in the first 30 seconds. In $S M$, there is more volatility throughout the round. There are often substantial moves of the provisional outcome between the 40th and 60th second. After that movements are rare and small in magnitude. The difference in volatility 
reflects the preceding discussion. The increase in volatility towards the end of the round in $S M$ could reflect some residual "sniping" attempts.

\section{A.2 Voting behavior}

The voting mechanisms differ substantially across the two mechanisms: in $S M$ individuals submit a single vote, while in $M A$ voters submit an interval. A comparison of behavior across treatments is therefore not warranted. However, as we discus below, voting behavior in both treatments is generally in line with the theoretical predictions regarding equilibrium play.

\section{A.2.1 Median Approval}

To compare voting behavior to the equilibrium predictions in $M A$ it is useful to reduce vote intervals to a one-dimensional object. As explained in Section 3.1, there is always a unique Nash equilibrium outcome for a group. Moreover, in equilibrium, the number of votes cast to alternatives on the right of the outcome net of the votes cast to alternatives on the left of the outcome, is also unique for every player. Let us define this quantity as $\delta\left(b, x^{*}\right)=\max \left\{b_{h i g h}-x^{*}, 0\right\}-\max \left\{x^{*}-b_{\text {low }}, 0\right\}$, where the interval $b=\left[b_{\text {low }}, b_{\text {high }}\right]$ represents a vote interval and $x^{*}$ represents the unique Nash equilibrium outcome.

Figure 8 shows a histogram of the differences between the $\delta$ predicted by Nash equilibrium $\left(\delta\left(b^{*}, x^{*}\right)\right)$ and that observed in the experimental data $\left(\delta\left(b^{o b s}, x^{*}\right)\right)$. It is clear from this graph that the $\delta$ 's as calculated from the experimental data are tightly centered around the Nash predictions.

To better understand the submitted vote intervals and how close they are to equilibrium predictions one is referred to Figure 9. The graphs on the first row show how the distribution of the vote interval limits look like in equilibrium according to the voter type. For medians with a starting point in $h_{2}^{0} \in$ $(33,67)$ there are multiple equilibrium vote intervals. For these cases in the histogram in the upper

middle panel of Figure 9, we randomly choose one of those equilibrium vote intervals for each voter. In all other cases there is a unique vote interval prediction. The graphs in the bottom row of the figure show the distribution of vote interval limits we observe in the experiment. 


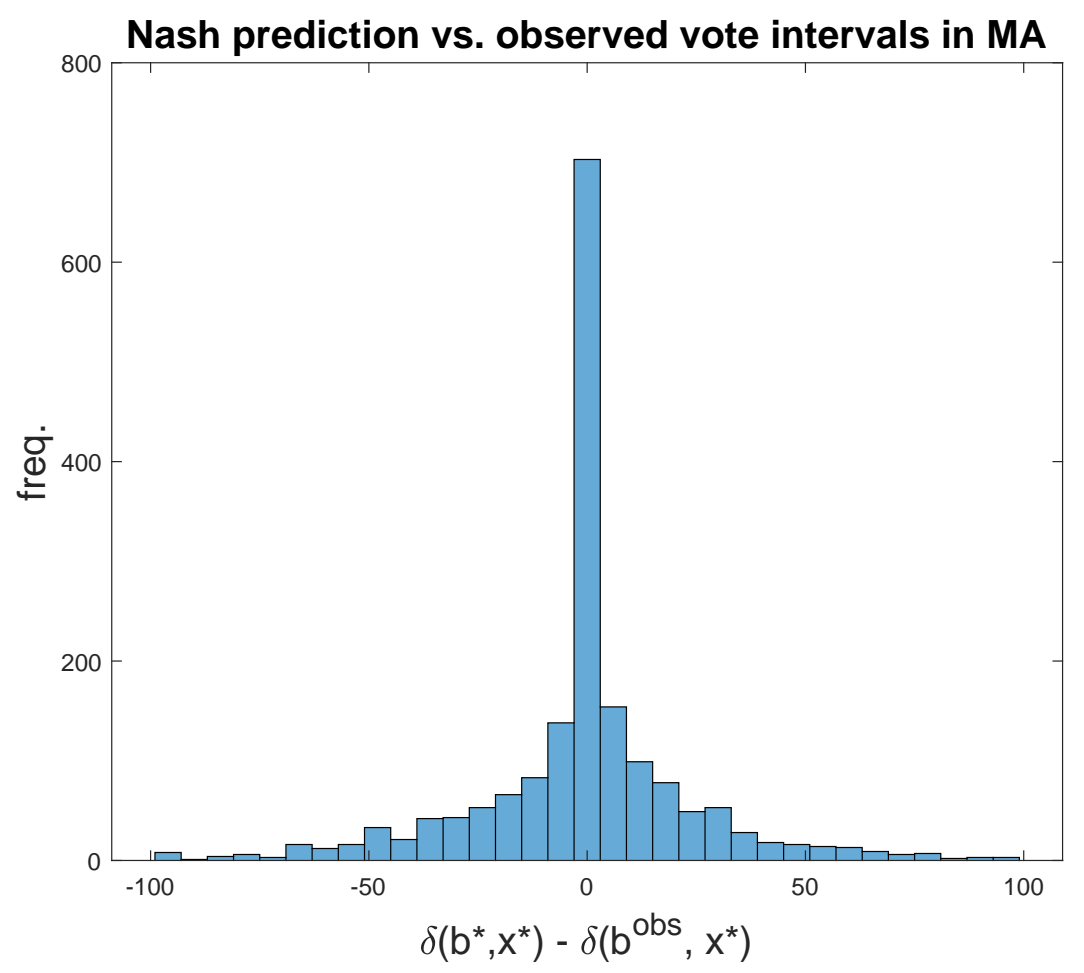

Figure 8: Difference between the predicted $\delta\left(b^{*}, x^{*}\right)$ and that observed in the data, $\delta\left(b^{\text {obs }}, x^{*}\right)$. The mode of the distribution is on 0 , with $26.8 \%$ of cases. The mean is -1.1 , and the st. deviation is 24.5 .
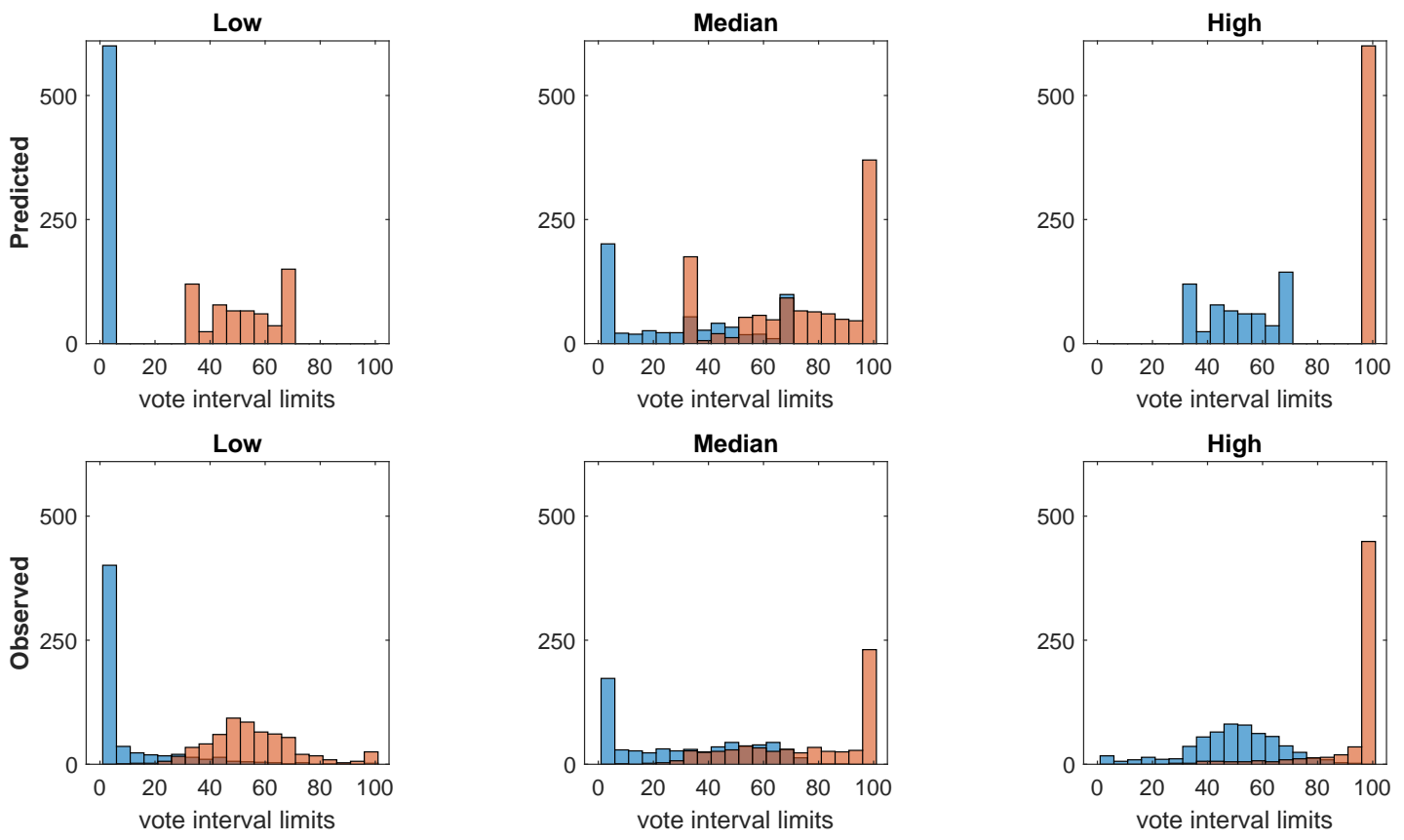

Figure 9: Vote interval limits according to type in MA. The first row of graphs shows the equilibrium prediction for the distribution of vote interval limits of voters with the lowest, median and highest starting point within each group in the $M A$ treatment. The second row show the distribution observed in the experiment. The blue and orange histograms correspond to the left and right limits respectively. 
Again, behavior appears close to the theoretical predictions. In particular, extreme voters almost always submit intervals with one limit on the extreme of the policy space that is on the same side of other's starting points as their own starting point, and the same is true in many cases for median voters. As discussed above, this is in line with equilibrium play. This is evident in Figure 9 by the substantial peaks on the extremes that match the theoretical prediction. Behavior is less in accordance with equilibrium regarding the interior limits of the voting intervals. One can see in Figure 9 that these are more dispersed in the experiment than what is predicted in theory.

\section{A.2.2 Simple Mean}

For $S M$ the equilibrium prediction is that the two extreme voters always vote for the corresponding extreme of the policy space. Similarly, medians with a starting point below 33 or above 67 also vote for the corresponding extreme. Medians with a starting point between these two values are predicted to vote for a point $b_{2}$ such that the mean of all three votes falls exactly on their starting point, i.e. $b_{2}^{*}=3 h_{2}^{0}-101$ (or the nearest integer). Figure 10 shows the distribution of the differences between predicted votes and those observed in the experiment. Nash equilibrium is a very good predictor of voting behavior in SM. In most cases individual votes exactly coincide with the equilibrium prediction, while the remaining votes are also very close.

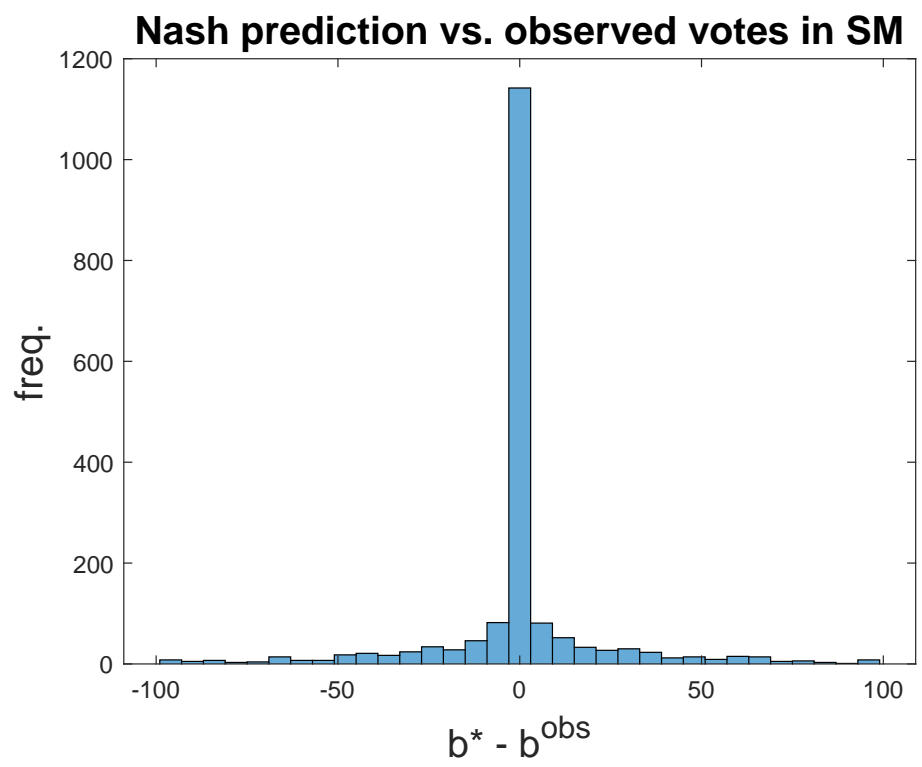

Figure 10: Difference between the predicted votes $b^{*}$ and the ones observed in the data, $b^{\text {obs }}$. The mode of the distribution is on 0 , with $54.1 \%$ of cases. The mean is -0.2 , and the st. deviation is 22.7 .

Since voting in the experiment closely resembles equilibrium voting, we also expect to find the 
polarization predicted by theory for $S M$. This is depicted in Figure 11. The resulting distribution of equilibrium votes for the starting point combination used in the experiment are show in the upper row of graphs in Figure 11.
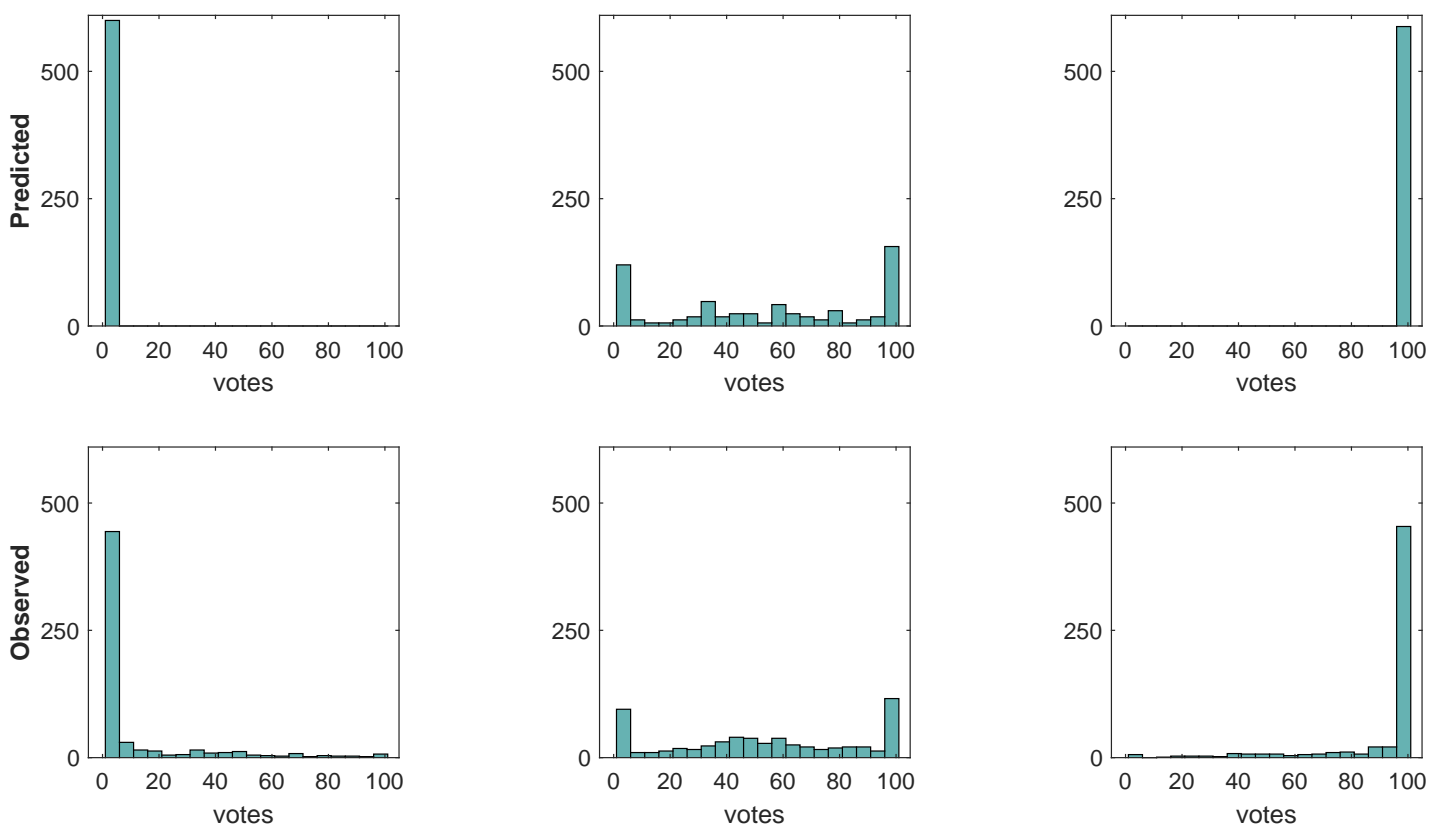

Figure 11: Votes according to type in SM. The first row of graphs shows the equilibrium prediction for the distribution of votes with the lowest, median and highest starting point within each group in the $S M$ treatment. The second row show the distribution observed in the experiment.

The bottom row shows the distribution of votes by voter type observed in the experiment. It is clear from the comparison of the two rows in Figure 11 that voting behavior generally conforms to equilibrium predictions. Nevertheless, there is a non-trivial number of deviations. Since a single voter deviation is enough to shift the outcome away from the equilibrium prediction, the high level of conformity between observed voting behavior and equilibrium predictions remains compatible with the visibly smaller degree of conformity between predictions and observed outcomes, as they are shown in Figure 3. 


\section{A.3 Similarity of outcomes across treatments}

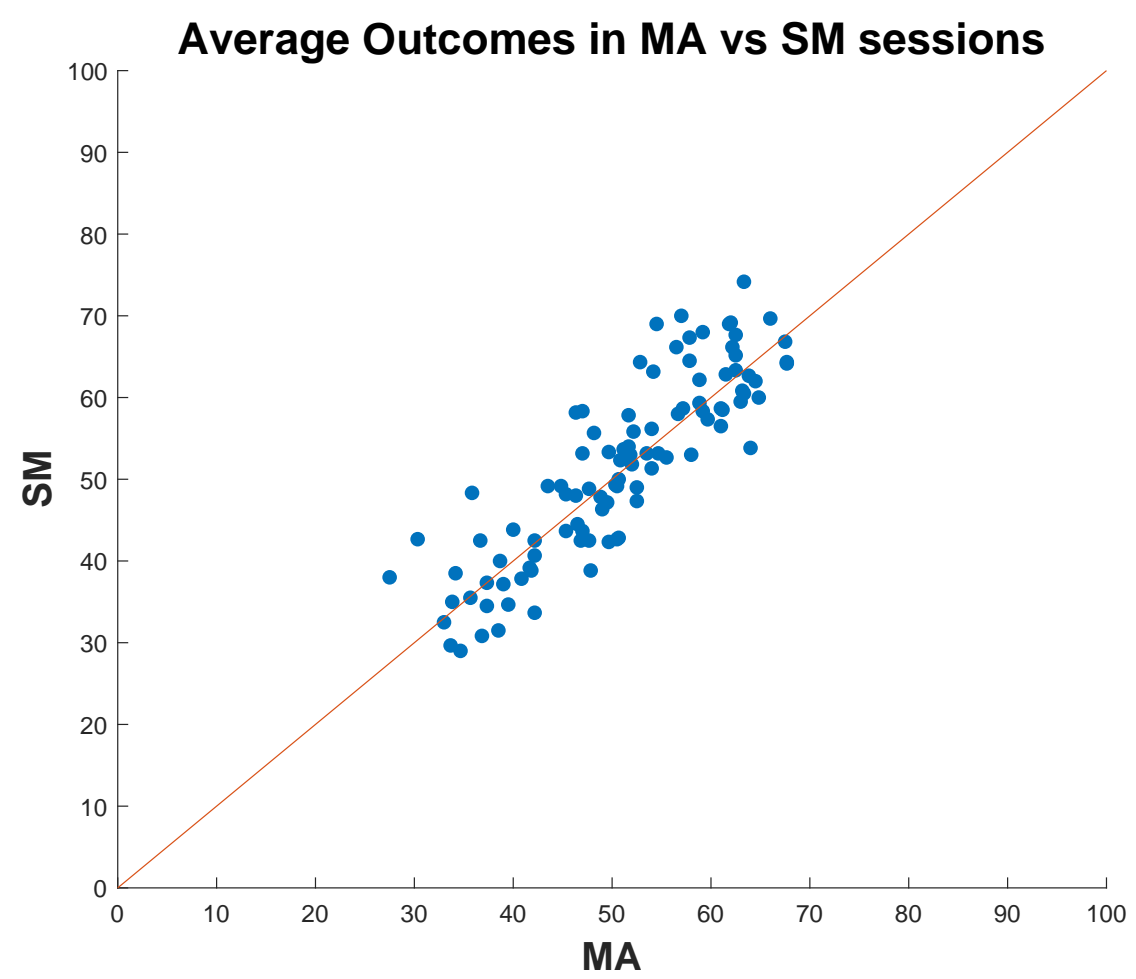

Figure 12: Average outcomes for the same set of starting points. Each point in the scatter plot corresponds to a unique set of starting points. Values in the horizontal axis represent the average outcome obtained for the particular set of starting points in all sessions in the $M A$ treatment. Values in the vertical axis represent the same for sessions in the $S M$ treatment. The solid line is the 45 degree axis. If outcomes were exactly the same across all sessions in both treatments, all points would lie on the diagonal. Outcomes were not restricted, but starting point combinations were selected in a way that the equilibrium outcome should lie between 33 and 67. This explains the concentration of the observed averages in the particular interval. 


\section{A.4 Can the treatment effect on agreement be explained by other differ- ences?}
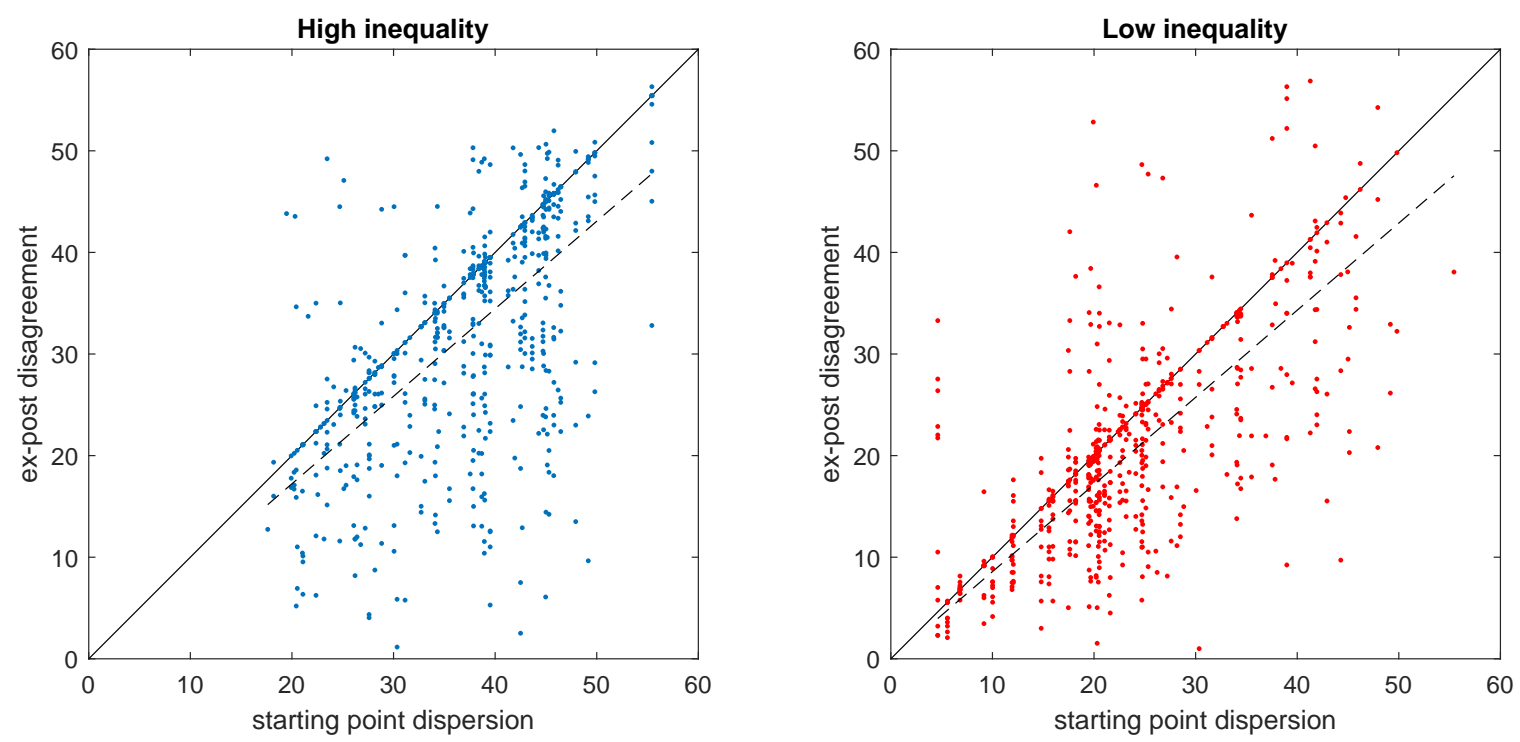

Figure 13: Disagreement conditional on starting points, split by inequality. Each point in the scatter plots corresponds to a group in one round. Values in the horizontal axis represent starting point dispersion, measured by the standard deviation of group members' starting points. Values in the vertical axis represent ex-post disagreement measured by the standard deviation of group members' proposals in Part B. The solid black lines are the 45 degree axis. Dashed lines indicate the best fit of a linear model with no constant to the corresponding data. 

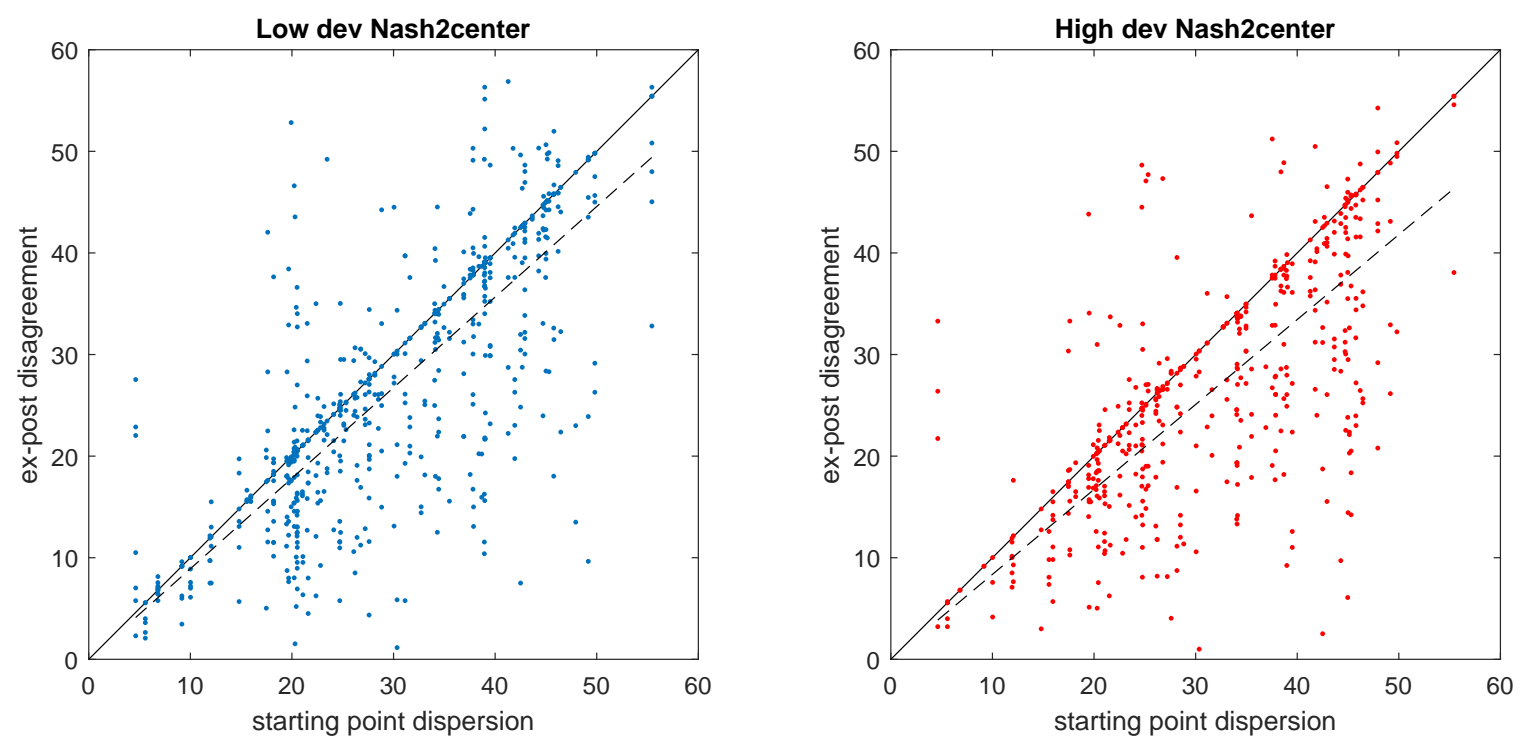

Figure 14: Disagreement conditional on starting points, split by deviation from Nash to center. Each point in the scatter plots corresponds to a group in one round. Values in the horizontal axis represent starting point dispersion, measured by the standard deviation of group members' starting points. Values in the vertical axis represent ex-post disagreement measured by the standard deviation of group members' proposals in Part B. The solid black lines are the 45 degree axis. Dashed lines indicate the best fit of a linear model with no constant to the corresponding data.

\section{A.5 Other-regarding Preferences and Reciprocity}

Here we test whether subjects' proposals in Part B are affected by other considerations apart from (or instead of) the Part A outcome. This could be the case especially if subjects' preferences are otherregarding. One possibility is that subjects are averse to inequality: i.e. they might favor proposals that reduce the degree of inequality. Mathematically this can be introduced into our simple framework by allowing individuals to put a weight on the point that minimizes inequality. In our setup this is the midpoint between the two extreme voters in each group. Another possibility is that subjects want to make proposals that benefit directly the other voters. Again this can be added to the model by allowing individuals to put a weight on other players' starting points (OPSP's).

In column 1 of Table 6 we show our estimate of the baseline model with treatment effects presented in the main text. In column 2 we re-estimate the model allowing for other-regarding preferences as described. We do not find evidence for such preferences. We cannot reject at any standard level of significance that the coefficients of the inequality maximizer, and other players' starting points are 
simultaneously equal to zero.

One final possibility is that subjects' behavior in Part B is driven by reciprocity. In that case one might want to favor other voters only when she feels that they were kind to her, and she might want to punish them if the opposite is true. To test for this we construct a measure of kindness as follows. Consider voters $i, j$ and $k$. To calculate how kind $j$ is being towards $i$, from $i$ 's perspective, we first find the best possible outcome for $j$ keeping $i$ and $k$ 's votes fixed. That is, we calculate what is the best $j$ can do for himself. Any deviation of the final outcome from this optimum can be viewed as a sacrifice made by $j$. To determine whether that sacrifice can be considered as kind or unkind towards $i$ we look at whether it has increased or decreased $i$ 's payoffs. The larger the sacrifice by $j$ that increases $i$ 's payoffs the more kind we consider $j$ to be towards $i$. If the sacrifice decreases $i$ 's payoff then it is considered as unkind: kindness will be negative. Formally, we calculate the kindness shown by $j$ to $i$ as:

$$
\operatorname{kindness}_{i j}=\operatorname{sign}\left(\pi_{i}(x)-\pi_{i}\left(o_{j}\right)\right) \times \frac{\left(o_{j}-x\right)}{\pi_{j}\left(o_{j}\right)}
$$

where $x$ is the Part A outcome, $\pi_{i}(x)$ is $i$ 's payoff from outcome $x$ and $o_{j}$ is the outcome that $j$ could achieve given others' votes, and would maximize his payoff. Given this definition, $k i n d n e s s_{i, j} \in[-1,1]$.

In column 3 of Table 6 we add the interaction of other's starting points with the corresponding kindness they showed in Part A. Despite the coefficient of interaction term for the Furthest OPSP and kindness being significant at the $5 \%$ level, using a joint test we cannot reject that the coefficients for Furthest OPSP and Furthest OPSP $\times$ kindness are simultaneously equal to zero. Overall, there does not seem to be support for reciprocity explaining subjects' behavior in our experiment. Different specifications for kindness yield similar results. 
TABle 6: Other-Regarding Preferences and Reciprocity

Dependent variable: proposals

\begin{tabular}{|c|c|c|c|}
\hline & $(1)$ & (2) & (3) \\
\hline Part A outcome & $\begin{array}{c}0.275^{* *} \\
{[.202, .347]}\end{array}$ & $\begin{array}{c}0.273^{* *} \\
{[.197, .349]}\end{array}$ & $\begin{array}{c}0.276^{* *} \\
{[.203, .351]}\end{array}$ \\
\hline $\begin{array}{l}\text { Part A outcome } \\
\times S M\end{array}$ & $\begin{array}{l}-0.215^{* *} \\
{[-.292,-.137]}\end{array}$ & $\begin{array}{l}-0.214^{* *} \\
{[-.293,-.136]}\end{array}$ & $\begin{array}{c}-0.213^{* *} \\
{[-.292,-.133]}\end{array}$ \\
\hline Starting point & $\begin{array}{c}0.722^{* *} \\
{[.661, .783]}\end{array}$ & $\begin{array}{c}0.726^{* *} \\
{[.638, .813]}\end{array}$ & $\begin{array}{c}0.725^{* *} \\
{[.633, .817]}\end{array}$ \\
\hline $\begin{array}{l}\text { Starting point } \\
\times S M\end{array}$ & $\begin{array}{c}0.206^{* *} \\
{[.137, .274]}\end{array}$ & $\begin{array}{c}0.205^{* *} \\
{[.136, .274]}\end{array}$ & $\begin{array}{c}0.206^{* *} \\
{[.136, .276]}\end{array}$ \\
\hline Inequality minimizer & & $\begin{array}{c}0.010 \\
{[-.125, .147]}\end{array}$ & $\begin{array}{c}0.011 \\
{[-.124, .146]}\end{array}$ \\
\hline Furthest OPSP & & $\begin{array}{c}0.005 \\
{[-.049, .059]}\end{array}$ & $\begin{array}{c}0.004 \\
{[-.050, .059]}\end{array}$ \\
\hline $\begin{array}{l}\text { Furthest OPSP } \\
\times \text { kindness }\end{array}$ & & & $\begin{array}{c}0.048^{*} \\
{[.000, .097]}\end{array}$ \\
\hline Closest OPSP & & $\begin{array}{c}-0.006 \\
{[-.050, .038]}\end{array}$ & $\begin{array}{c}-0.008 \\
{[-.052, .035]}\end{array}$ \\
\hline $\begin{array}{l}\text { Closest OPSP } \\
\times \text { kindness }\end{array}$ & & & $\begin{array}{c}-0.093 \\
{[-.189, .008]}\end{array}$ \\
\hline Constant & $\begin{array}{c}0.633 \\
{[-.892,2.169]}\end{array}$ & $\begin{array}{c}-0.017 \\
{[-1.514,1.483]}\end{array}$ & $\begin{array}{c}-0.168 \\
{[-1.77,1.472]}\end{array}$ \\
\hline$R^{2}$ & .839 & .839 & .840 \\
\hline Observations & 3600 & 3600 & 3600 \\
\hline
\end{tabular}

Notes: Confidence intervals (95\%) and p-values are obtained using wild cluster bootstrap, with robust errors clustered at the session and subject level (see (Cameron et al., 2008), (MacKinnon and Webb, 2018) and (Roodman et al., 2018)). SM is a dummy variable and is equal to one for treatment $S M$. Inequality minimizer is the point that minimizes inequality as measured by the Gini coefficient or the maxmin criterion. This is obtained by calculating the midpoint between the two extreme starting points. Furthest (closest) OPSP refers to the other players' starting point (OPSP) that is furthest away (closest to) one's own starting point. Kindness can take values from -1 to 1 . It is a measure of how 'kind' another voter's Part A vote can be considered.

${ }^{* *}: p-v a l<.01,{ }^{*}: p-v a l<.05$ 


\section{A.6 Other tables}

TABLE 7: OLS RESUlTS - SAMPLE SPLIT BASED ON INEQUALITY

Dependent variable: proposals

\begin{tabular}{|c|c|c|c|c|c|c|}
\hline & \multicolumn{2}{|c|}{$\begin{array}{c}\text { All } \\
\text { treatments }\end{array}$} & \multicolumn{2}{|c|}{ MA } & \multicolumn{2}{|c|}{ SM } \\
\hline & $\begin{array}{c}\text { High } \\
\text { inequality } \\
(1)\end{array}$ & $\begin{array}{c}\text { Low } \\
\text { inequality } \\
\text { (2) }\end{array}$ & $\begin{array}{c}\text { High } \\
\text { inequality } \\
\text { (3) }\end{array}$ & $\begin{array}{c}\text { Low } \\
\text { inequality } \\
\text { (4) }\end{array}$ & $\begin{array}{c}\text { High } \\
\text { inequality } \\
\text { (5) }\end{array}$ & $\begin{array}{c}\text { Low } \\
\text { inequality } \\
\text { (6) }\end{array}$ \\
\hline $\begin{array}{l}\text { Part A outcome } \\
(\hat{\beta})\end{array}$ & $\begin{array}{c}0.138^{* *} \\
{[0.046,0.235]}\end{array}$ & $\begin{array}{c}0.179^{* *} \\
{[[0.077,0.282]}\end{array}$ & $\begin{array}{c}0.317^{* *} \\
{[0.203,0.436]}\end{array}$ & $\begin{array}{c}0.270^{*} \\
{[0.139,0.408]}\end{array}$ & $\begin{array}{c}0.035 \\
{[-0.006,0.076]}\end{array}$ & $\begin{array}{c}0.072 \\
{[-0.106,0.239]}\end{array}$ \\
\hline Starting point & $\begin{array}{c}0.831^{* *} \\
{[0.757,0.905]}\end{array}$ & $\begin{array}{c}0.814^{* *} \\
{[0.732,0.895]}\end{array}$ & $\begin{array}{c}0.721^{* *} \\
{[0.659,0.784]}\end{array}$ & $\begin{array}{c}0.729^{* *} \\
{[0.624,0.827]}\end{array}$ & $\begin{array}{c}0.930^{* *} \\
{[0.886,0.976]}\end{array}$ & $\begin{array}{c}0.914^{* *} \\
{[0.827,1.004]}\end{array}$ \\
\hline Constant & $\begin{array}{c}1.835 \\
{[-0.310,3.957]}\end{array}$ & $\begin{array}{c}0.498 \\
{[-1.571,2.548]}\end{array}$ & $\begin{array}{c}-1.231 \\
{[-5.466,3.085]}\end{array}$ & $\begin{array}{c}0.168 \\
{[-2.316,2.594]}\end{array}$ & $\begin{array}{c}1.818 \\
{[-0.970,4.591]}\end{array}$ & $\begin{array}{c}0.878 \\
{[-3.904,5.898]}\end{array}$ \\
\hline$R^{2}$ & .830 & .825 & .765 & .809 & .900 & .852 \\
\hline Observations & 1818 & 1782 & 867 & 933 & 951 & 849 \\
\hline
\end{tabular}

Notes: Confidence intervals (95\%) and p-values are obtained using wild cluster bootstrap, with robust errors clustered at the session and subject level (see (Cameron et al., 2008), (MacKinnon and Webb, 2018) and (Roodman et al., 2018)). Columns 1, 3 and 5 use the groups in the sample where the Part A outcome resulted in higher (above average) inequality. The remaining columns use the groups in the sample where inequality is below average.

${ }^{* *}: p-v a l<.01, *: p-v a l<.05$ 
TABLE 8: TWO-PART MODEL - USING A BINARY OR COMBINATION OF MEASURES FOR MANIFEST SUPPORT

Dependent variable: $\tilde{\beta}_{i r}$, the weight on the Part $A$ result

\begin{tabular}{|c|c|c|c|c|c|c|}
\hline \multirow{3}{*}{ First-part: prob } & \multicolumn{2}{|c|}{$\begin{array}{c}\text { Full } \\
\text { Sample }\end{array}$} & \multicolumn{2}{|c|}{ MA } & \multicolumn{2}{|c|}{ SM } \\
\hline & $(1)$ & $(2)$ & (3) & (4) & (5) & (6) \\
\hline & & & & & & \\
\hline Constant & -0.104 & & -0.185 & & $-0.356^{*}$ & \\
\hline & $(.394)$ & & $(.156)$ & & $(.029)$ & \\
\hline Treatment & $-0.334^{*}$ & & & & & \\
\hline$(\mathrm{SM}=1)$ & $(.0394)$ & & & & & \\
\hline Voter type & 0.131 & & $0.241^{*}$ & & 0.011 & \\
\hline$($ Non-median $=1)$ & $(.092)$ & & $(.020)$ & & $(.920)$ & \\
\hline Own support & $0.192^{*}$ & & $0.200^{* *}$ & & 0.305 & \\
\hline$\left(\left\{x \in b_{i}\right\}=1\right)$ & $(.011)$ & & $(.009)$ & & $(.551)$ & \\
\hline Second-part: & & & & & & \\
\hline Constant & 0.191 & -0.610 & -0.017 & $-1.151^{* *}$ & 0.253 & -0.112 \\
\hline & $(.422)$ & $(.466)$ & $(.913)$ & $(.005)$ & $(.546)$ & $(.911)$ \\
\hline Treatment & -0.184 & 0.000 & & & & \\
\hline$(\mathrm{SM}=1)$ & $(.228)$ & $(.999)$ & & & & \\
\hline Voter type & 0.203 & 0.265 & $0.436^{*}$ & $0.428^{*}$ & -0.140 & -0.055 \\
\hline$($ Non-median $=1)$ & $(.363)$ & $(.168)$ & $(.021)$ & $(.023)$ & $(.758)$ & $(.893)$ \\
\hline Own support & 0.131 & & 0.185 & & -0.120 & \\
\hline$\left(\left\{x \in b_{i}\right\}=1\right)$ & $(.329)$ & & $(.167)$ & & $(.935)$ & \\
\hline Own support & & 0.877 & & $1.310^{* *}$ & & 0.460 \\
\hline (continuous) & & $(.351)$ & & $(.009)$ & & $(.633)$ \\
\hline Log-likelihood & -6166.1 & -6165.2 & -3327.9 & -3327.9 & -2753.1 & -2753.0 \\
\hline Observations & 3416 & 3416 & 1737 & 1737 & 1679 & 1679 \\
\hline
\end{tabular}

Notes: The numbers in parenthesis are the p-values that are obtained using wild cluster bootstrap, with robust errors clustered at the session and subject level.

$* *: p-v a l<.01$

$*: p-v a l<.05$ 


\section{B Instructions}

The experiment was run in Greek. We present here a translation of the instructions done by the authors. Original instructions in Greek are available upon request.

\section{B.1 Treatment $S M$}

Thank you for participating in this session. Please remain quiet. The experimental session will be run using a computer and all answers will be given through it. Please do not talk to each other and keep quiet during the session. Please note that the use of mobile phones and other electronic devices is not permitted. Please read the instructions carefully, and if you have any questions, raise your hand. The answer that will be given will be announced to everyone.

\section{General Instructions}

During the experiment, you can win points. The points will be converted into euros. 1 euro $=\mathbf{1 5}$ points. Each participant will receive a payment. The exact amount you will receive depends on the decisions you will make during the experiment, the decisions of other participants and also on luck. In addition, you will receive the amount of $€ \mathbf{3}$ as a show-up fee. Following the completion of the experimental session, a fee will be paid privately in cash to each one of you. The experiment consists of two parts. The instructions below are for Part A of the experiment. Following the completion of Part A, the instructions of Part B will be given. Your final earnings will be:

\section{$€ 3$ show-up fee + earnings in Part $A+$ earnings in Part B}

\section{Part A}

\section{Aim}

Part A of the experiment consists of 20 periods. In each period, you will be in a three-member group with two other participants. The aim of the group is to choose a common destination from 100 consecutive locations (that is, an integer from 1 to 100) which will be the final decision of the group in the end of each period. The composition of the groups will change in every single period, and you will not be able 
to know the identity of the members of the group. The way the destination is chosen from the group will be explained below. First, we will explain the way in which the payoffs of each player are determined.

\section{Starting points and payoffs}

In each period, a specific destination (that is, an integer from 1 to 100) will be chosen as an individual starting point. The payoffs in each period depend on the distance between the final destination that will be chosen and your individual starting point: The farther the destination is from the starting point of each player, the smaller his/her payoffs will be. Specifically, each player's payoff (in points) will be calculated as follows:

$$
\text { Profits }=100-\mid \text { destination }- \text { starting point } \mid
$$

Example:

The group chose the location 49 as a destination.

Player 1's starting point is 20. Player 1's payoff is 71 points. (The distance between the starting point of player 1 and the final (common) destination is $49-20=29$. So, the payoff is $100-29=71$ ).

Player 2's starting point is 50. Player 2's payoff is 99 points. (The distance between the starting point of player 2 and the final (common) destination is $50-49=1$. So, the payoff is $100-1=99$ )

Player 3's starting point is 95. Player 3's payoff is $\mathbf{5 4}$ points. (The distance between the starting point of player 1 and the final (common) destination is $95-49=46$. So, the payoff is $100-46=54$ )

The calculations above will be conducted automatically from the computer, and on the screen you will see your starting point, your group members' starting points, and their payoffs, depending on the chosen destination.

\section{Attention!}

- The starting point of each player will be different (unique).

- In each period, the starting points will change.

- All players' starting points will be shown in the screen with arrows.

- Each player's payoff will be indicated by a bar. The greater the payoff, the taller the bar. 


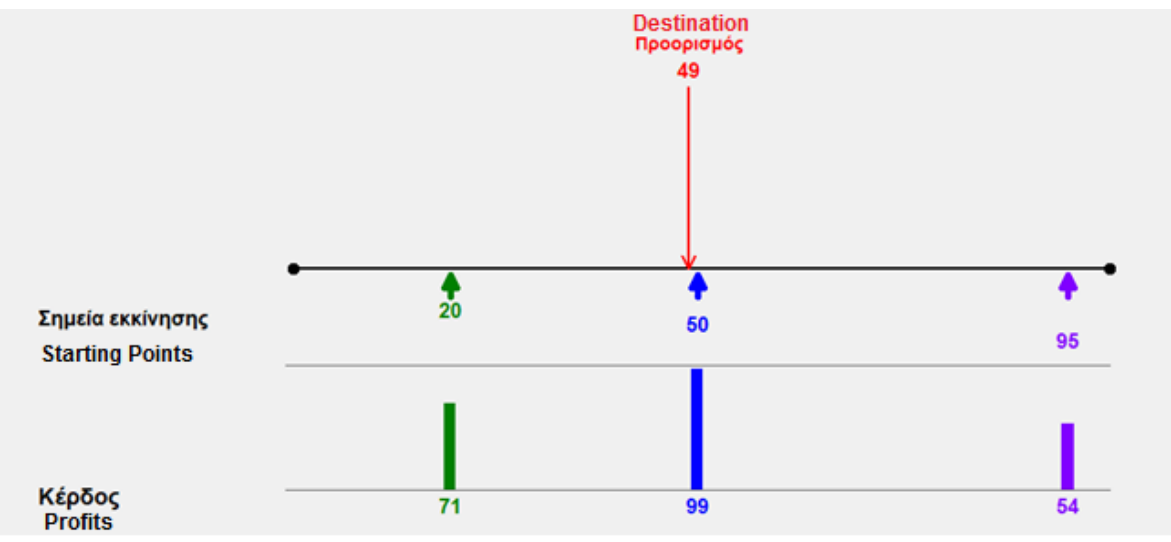

Figure 15

\section{Selection}

The selection of the destination will be done as follows: Each group member can vote for exactly one location. The final destination will be the average of all locations voted for by the group members. (In case of a non-integer average, the final destination will be calculated by rounding to the nearest integer).

\section{Example 1:}

Player 1 votes 5 .

Player 2 votes 80 .

Player 3 votes 95 .

The final destination will be the location 60 because the average of the chosen locations is: $\frac{5+80+95}{3}=$ 60

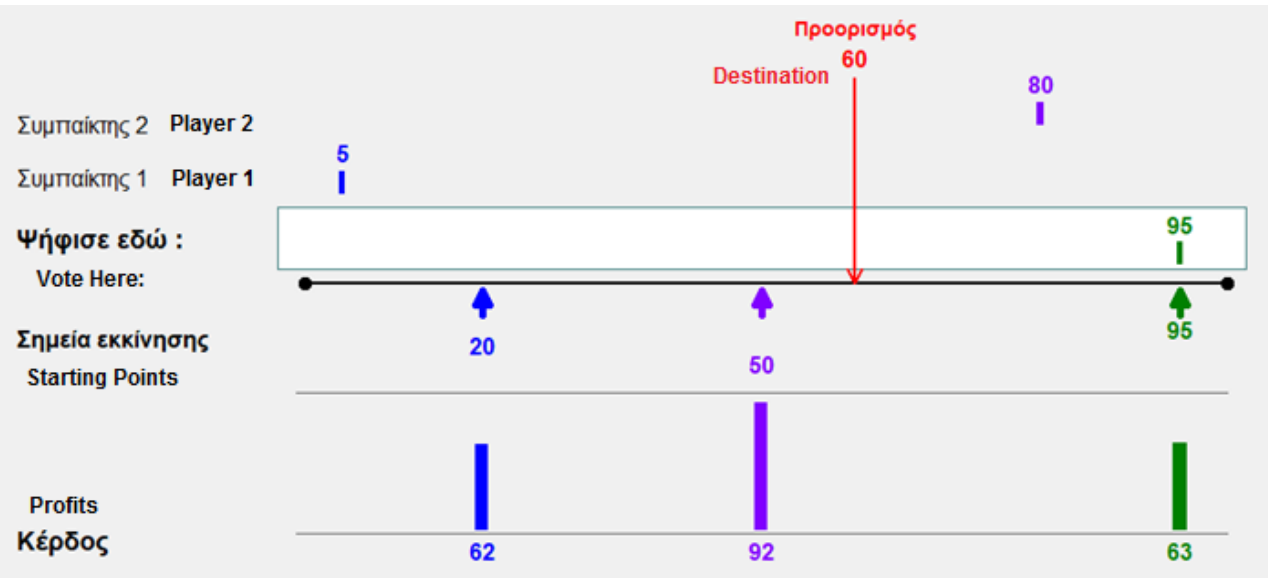

Figure 16 
Example 2:

Player 1 votes 30 .

Player 2 votes 80 .

Player 3 votes 95 .

The final destination will be the location 68 because the average of the chosen locations is: $\frac{30+80+95}{3} \approx$ 68,33

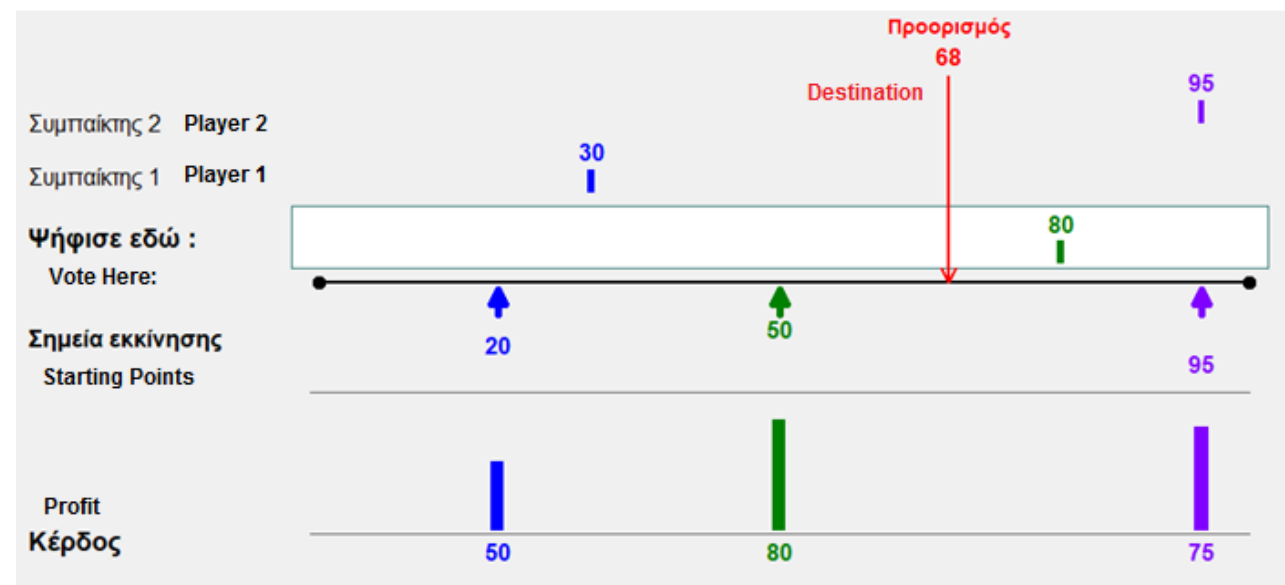

Figure 17

\section{Voting Procedure}

Every single period, the voting procedure will last $60+\mathrm{x}$ seconds, where $\mathrm{x}$ is a random number from 1 to 10. In other words, following the completion of the voting, the procedure will stop randomly in one of the next 10 seconds.

You can specify the location you are voting by clicking on the white frame you will see on your screen.
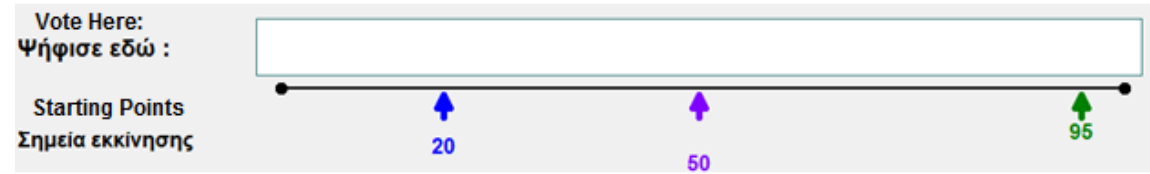

Figure 18

At the same time, you will see what other group members are voting for and how the common desti- 
nation is shaped. You can change your vote as many times as you want until the voting procedure is over.

The destination of each period will be determined after the completion of the voting procedure. Hence, make sure you have made your choice before the end of the 60-second period. In the first two periods, the duration will be $90+\mathrm{x}$ seconds, so as to allow you plenty of time to get used to the procedure. The remaining time will be shown at the bottom of your screen.

At the end of the experiment, one period from Part A will be selected randomly and your payment will be based on your earnings in this period. Hence, we encourage you to pay attention to all your decisions in all periods, since each of them can determine your final payment.

Before we start, there will be two trial periods to make sure everything is understood. These two trial periods cannot be chosen, and your decisions in those periods will not affect your payment.

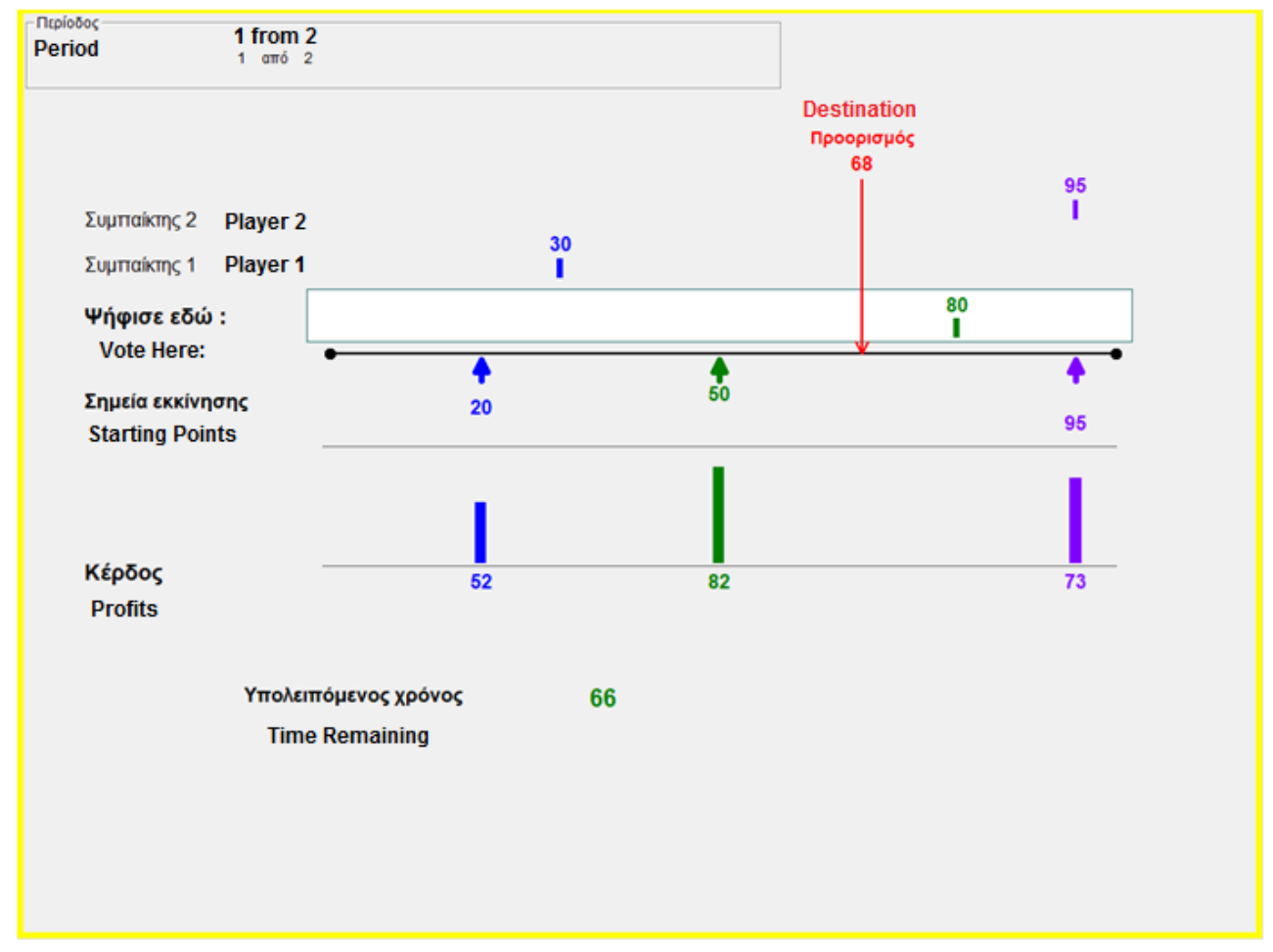

Figure 19 


\section{Part B}

This part again consists of 20 periods.

In each period you will be placed in the same group you were in the corresponding period of Part A, with the same individual starting points.

The aim of the group is to make a collective decision regarding your common destination.

At the top of your screen, you will see a figure in which the starting points, the votes of your teammates and the final chosen destination of the corresponding period of Part A will be displayed.

This time the final destination will be determined according to a new procedure. Click in the white frame at the middle of the screen to propose a destination. Your proposal will appear as well as each group member's payoff if your proposal is selected. You can change your proposal as many times as you like until you press the red button 'Submit'. When you press the button, your submission will be confirmed, and you will move to the next period. In this part, the proposals of your teammates will be unknown to you until the end of the experiment.

\section{One of the three proposals made by the members of each group will be chosen randomly} and become the new common destination for this period, according to which group members' payoffs will be determined.

The profits will be calculated in the same way as in Part A by taking into consideration the new destination.

At the end of the experiment, one period from Part B will be selected randomly and your payment will be based on your earnings in this period. Hence, we encourage you to pay attention to all your decisions in all periods, since each of them can determine your final payment.

Following the completion of the experiment, you will see on your screen the chosen periods for the 


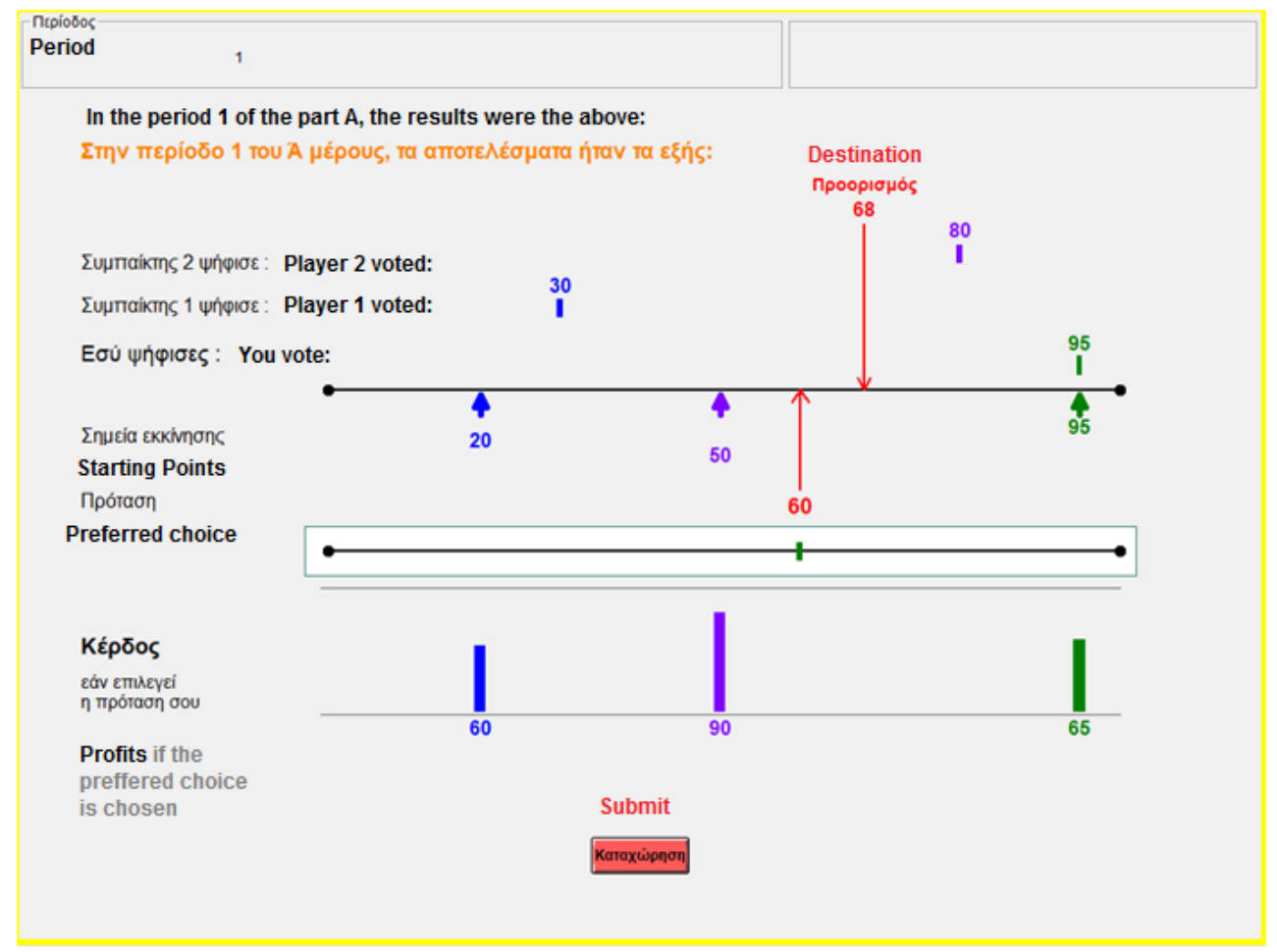

Figure 20

calculation of your profit, as well as your final profit.

\section{Treatment $M A$}

Thank you for participating in this session. Please remain quiet. The experimental session will be run using a computer, and all answers will be given through it. Please do not talk to each other and keep quiet during the session. Please note that the use of mobile phones and other electronic devices is not permitted. Please read the instructions carefully and if you have any questions, raise your hand. The answer that will be given will be announced to everyone.

\section{General Instructions}

During the experiment, you can win points. The points will be converted into euros. 1 euro $=15$ points. Each participant will receive a payment. The exact amount you will receive depends on the decisions you will make during the experiment, the decisions of other participants, and also on luck. In addition, you will receive the amount of $€ 3$ as a show-up fee. Following the completion of the 
experimental session, a fee will be paid privately in cash to each one of you. The experiment consists of two parts. The instructions below are for Part A of the experiment. Following the completion of Part A, the instructions of Part B will be given. Your final earnings will be:

$€ 3$ show-up fee + earnings in Part $A+$ earnings in Part B

\section{Part A}

\section{$\operatorname{Aim}$}

Part A of the experiment consists of 20 periods. In each period, you will be in a three-member group with two other participants. The aim of the group is to choose a common destination from 100 consecutive locations (that is, an integer from 1 to 100) which will be the final decision of the group in the end of each period. The composition of the groups will change in every single period, and you will not be able to know the identity of the members of the group. The way the destination is chosen from the group will be explained below. First, we will explain the way in which the payoffs of each player are determined.

\section{Starting points and payoffs}

In each period, a specific destination (that is, an integer from 1 to 100) will be chosen as an individual starting point. The payoffs in each period depend on the distance between the final destination that will be chosen and your individual starting point: The farther the destination is from the starting point of each player, the smaller his/her payoffs will be. Specifically, each player's payoff (in points) will be calculated as follows:

$$
\text { Profits }=100-\mid \text { destination }- \text { starting point } \mid
$$

Example:

The group chose the location 49 as a destination.

Player 1's starting point is 20. Player 1's payoff is 71 points. (The distance between the starting point of player 1 and the final (common) destination is $49-20=29$. So, the payoff is $100-29=71$ ). 
Player 2's starting point is 50. Player 2's payoff is 99 points. (The distance between the starting point of player 2 and the final (common) destination is $50-49=1$. So, the payoff is $100-1=99$ )

Player 3's starting point is 95. Player 3's payoff is $\mathbf{5 4}$ points. (The distance between the starting point of player 1 and the final (common) destination is $95-49=46$. So, the payoff is $100-46=54$ )

The calculations above will be conducted automatically from the computer, and on the screen you will see your starting point, your group members' starting points, and their payoffs, depending on the chosen destination.

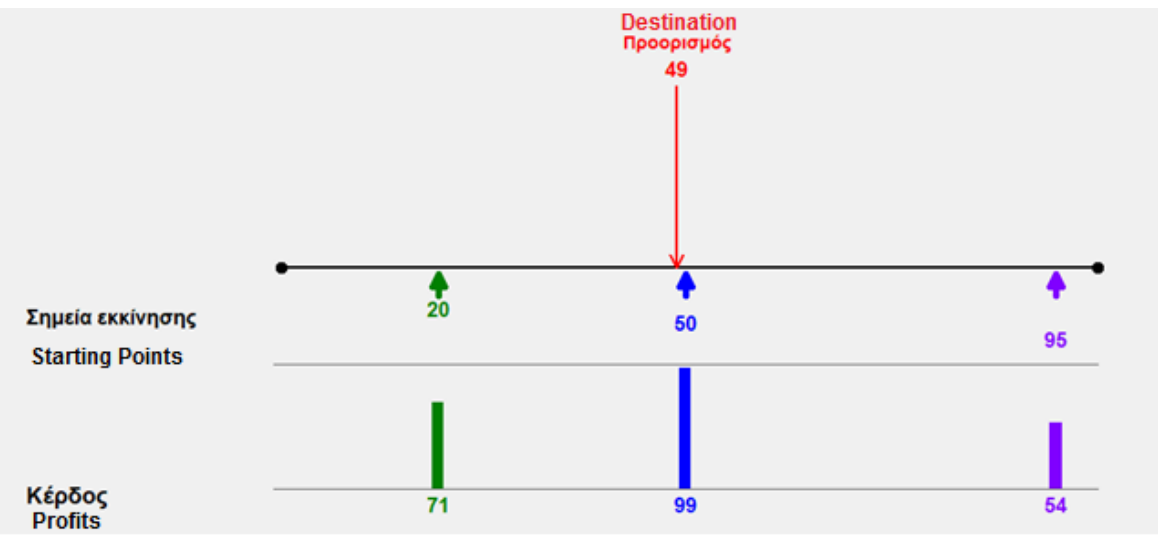

Figure 21

\section{Attention!}

- The starting point of each player will be different (unique).

- In each period, the starting points will change.

- All players' starting points will be shown in the screen with arrows.

- Each player's payoff will be indicated by a bar. The greater the payoff, the taller the bar.

\section{Selection}

The selection of the destination will be done as follows: Each group member can vote up to 100 locations. These locations should be consecutive (e.g. someone can vote from 23 to 56). The destination will be the largest median of the distribution of the votes. That is, destination $\mathrm{X}$ will be selected if at least half of the votes have been given to locations to the left of $\mathrm{X}+1$ and at least half of the votes have been given to locations to the right of X-1. If there are more than two locations with this feature, the largest one will be selected. 
Example 1:

Player 1 votes from 1 to 20 (20 votes).

Player 2 votes from 71 to 75 (5 votes).

Player 3 votes from 91 to 100 (10 votes).

The sum of the votes is 35 .

Every single location from 1 to 20, from 71 to 75 , and from 91 to 100 has been voted for once. The rest of the locations have not been voted for.

The destination will be location 18 (because the votes that have been given to locations to the left of $18+1$ are $18>35 / 2=17.5$, and the votes that have been given to locations to the right of $18-1$ are 18 $>35 / 2=17.5)$.

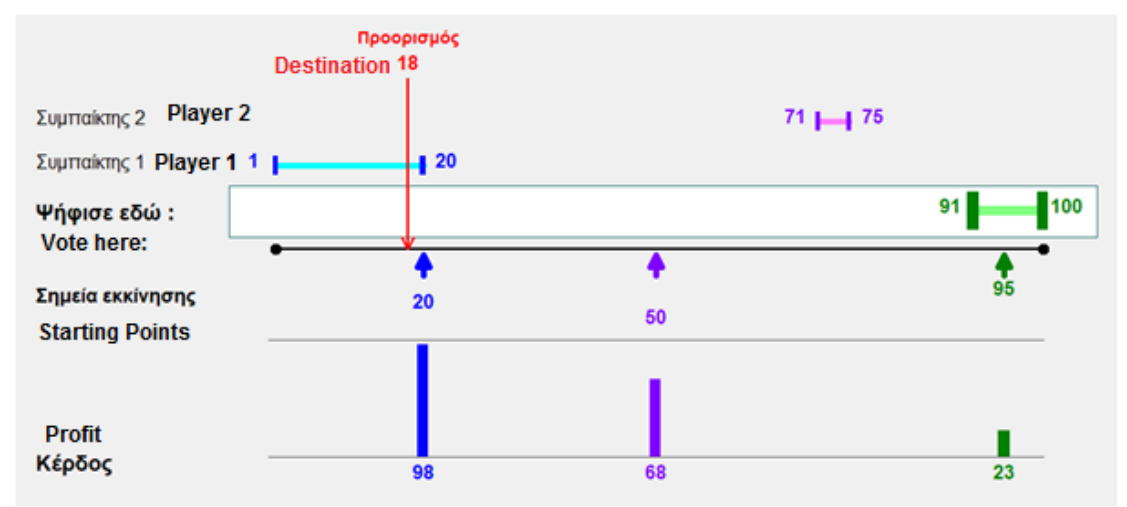

Figure 22

Example 2:

Player 1 votes from 1 to 20 (20 votes).

Player 2 votes from 71 to 75 (5 votes).

Player 3 votes from 71 to 100 (30 votes).

The sum of the votes is 55 .

Every single location from 71 to 75 has been voted for twice (by player 2 and player 3).

Every single location from 1 to 20 and from 76 to 100 has been voted for once.

The rest of the locations have not been voted for. 
The destination will be location 74 (because the votes that have been given to locations to the left of $74+1$ are $28>55 / 2=27.5$, and the votes that have been given to locations to the right of $74-1$ are 28 $>55 / 2=27.5)$.

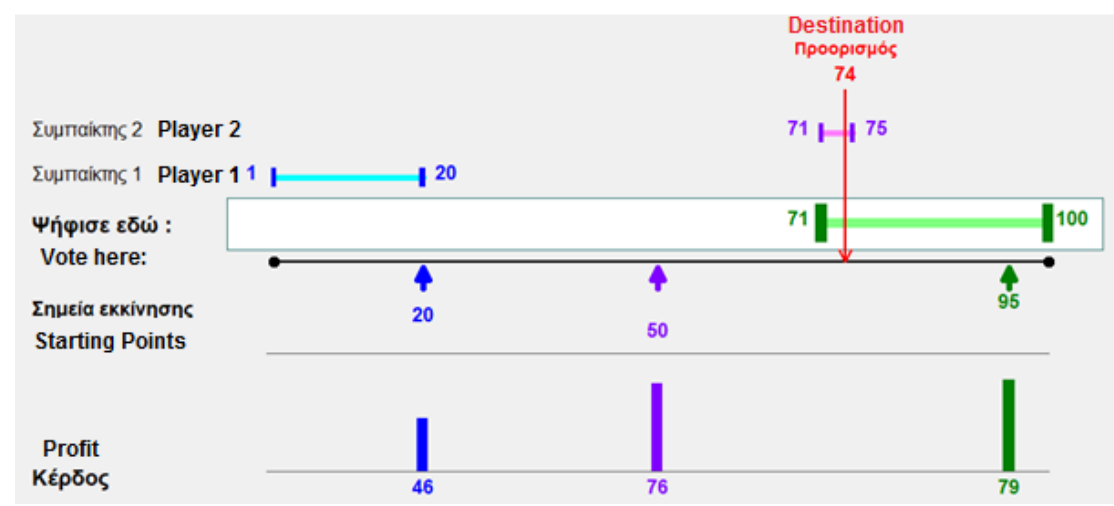

Figure 23

\section{Voting Procedure}

Every single period, the voting procedure will last $60+\mathrm{x}$ seconds, where $\mathrm{x}$ is a random number from 1 to 10. In other words, following the completion of the voting, the procedure will stop randomly in one of the next 10 seconds.

You can specify the locations you are voting for by clicking and by moving the green bars that you will see on your screen.

At the same time, you will see what your teammates are voting for and how the common destination is shaped. You can change your vote as many times as you want until the voting procedure is over.

The destination of each period will be determined after the completion of the voting procedure. Hence, make sure you have made your choice before the end of the 60 -second period. In the first two periods, the duration will be $90+\mathrm{x}$ seconds, so as to allow you plenty of time to get used to the procedure. The remaining time will be shown at the bottom of your screen.

At the end of the experiment, one period from Part A will be selected randomly, and your payment will be based on your earnings in this period. Hence, we encourage you to pay attention 
to all your decisions in all periods, since each of them can determine your final payment.

Before we start, there will be two trial periods to make sure everything is understood. These two trial periods cannot be chosen, and your decisions in those periods will not affect your payment.

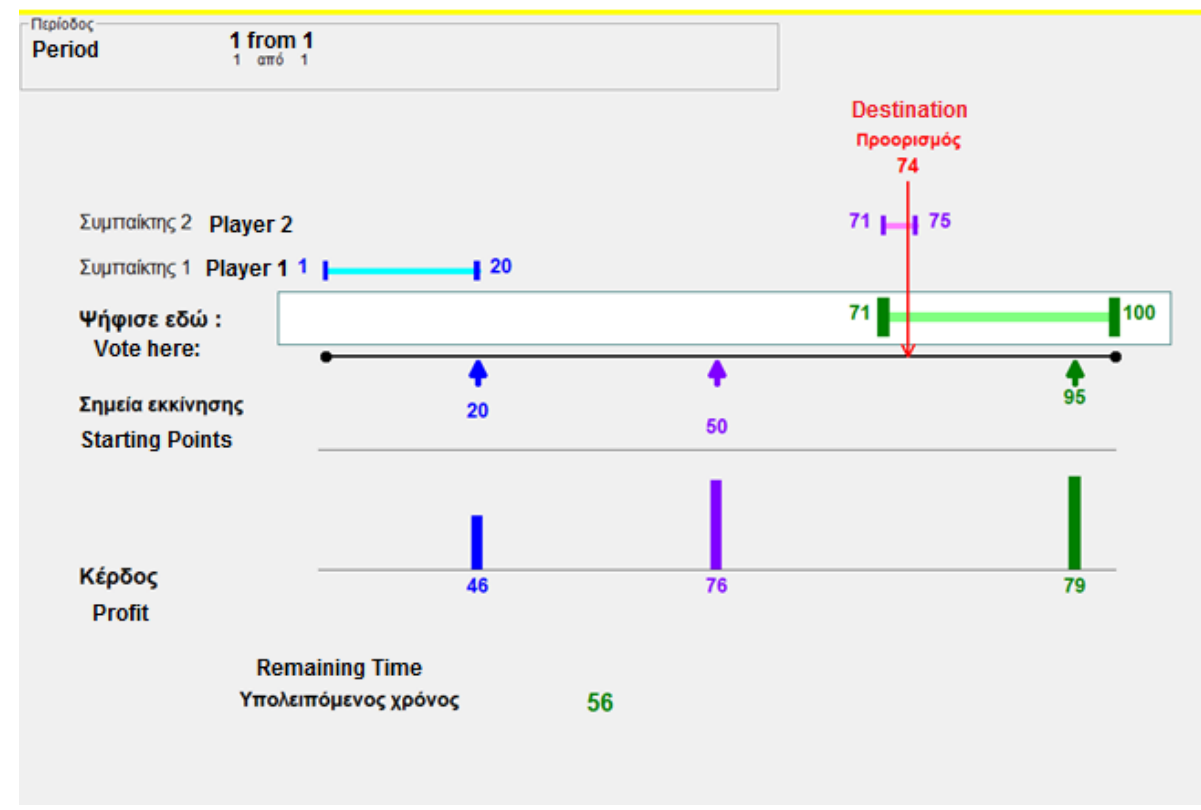

Figure 24 


\section{Part B}

This part, again, consists of 20 periods.

In each period you will be placed in the same group you were in the corresponding period of Part A, with the same individual starting points.

The aim of the group is to make a collective decision regarding your common destination.

At the top of your screen, you will see a figure in which the starting points, the votes of your teammates, and the final chosen destination of the corresponding period of Part A will be displayed.

This time the final destination will be determined according to a new procedure. Click on the white frame at the middle of the screen to propose a destination. Your proposal will appear, as well as each group member's payoff if your proposal is selected. You can change your proposal as many times as you like until you press the red button 'Submit'. When you press the button, your submission will be confirmed and you will move to the next period. In this part, the proposals of your teammates will be unknown to you until the end of the experiment.

\section{One of the three proposals made by the members of each group will be chosen randomly} and become the new common destination for this period, according to which group members' payoffs will be determined.

The profits will be calculated in the same way as in Part A by taking into consideration the new destination.

At the end of the experiment, one period from Part B will be selected randomly, and your payment will be based on your earnings in this period. Hence, we encourage you to pay attention to all your decisions in all periods, since each of them can determine your final payment.

Following the completion of the experiment, you will see on your screen the chosen periods for the 
calculation of your profit, as well as your final profit.

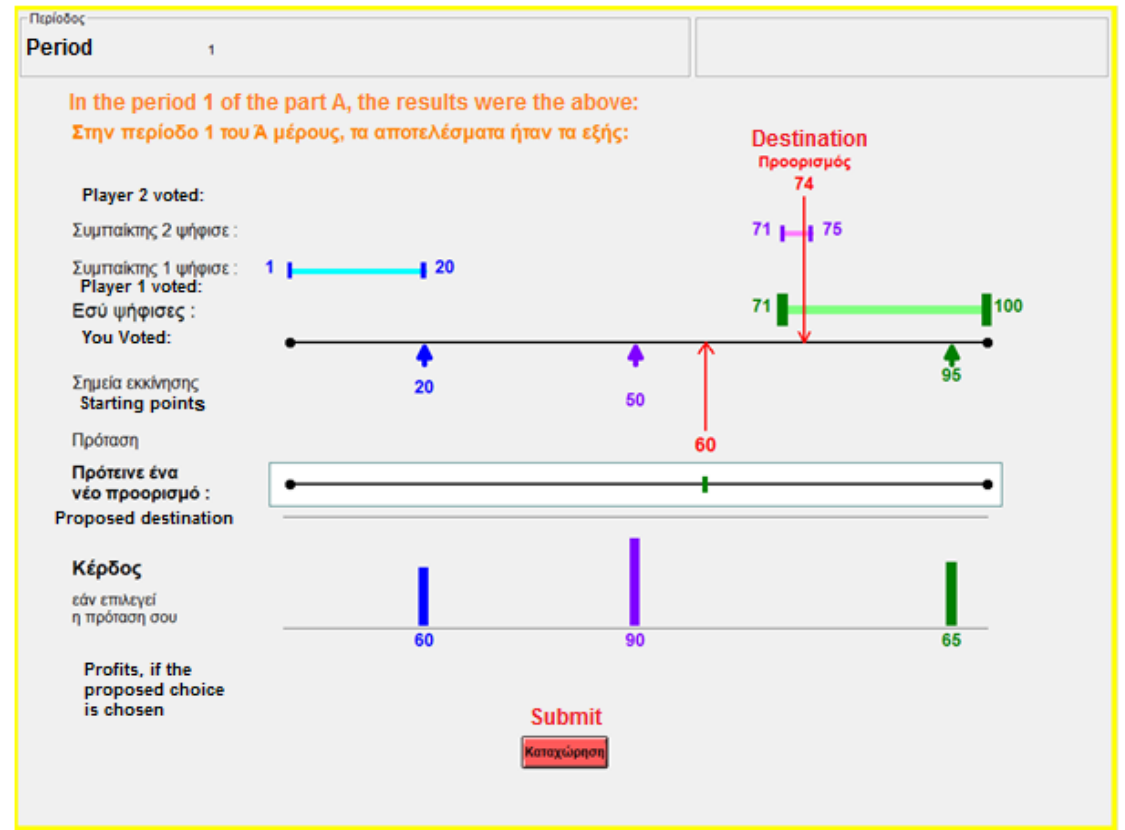

Figure 25 